\title{
Characterization on insulation performance, post- stability, and foaming process of rigid polyurethane sandwich panel for cold storage warehouse
}

\author{
Jie $\mathrm{Xu}^{1, *}$, Tao $\mathrm{Wu}^{2}$, Wei Sun ${ }^{3}$, Chuang Peng ${ }^{4, *}$ \\ ${ }^{1}$ PhD candidate, Department of Chemical and Environmental Engineering, Faculty of Science and Engineering, \\ University of Nottingham Ningbo Campus, Ningbo, China 315100. \\ ${ }^{2}$ Prof. Dr., Dean, Faculty of Science and Engineering, University of Nottingham Ningbo Campus, Ningbo, China \\ 315100 . \\ ${ }^{3}$ Prof. Dr., Department of Mechanical Engineering, Faculty of Engineering, University of Nottingham, \\ Nottingham, UK NG7 2RD. \\ ${ }^{4}$ Prof. Dr., School of Resource and Environment Sciences, Wuhan University, Wuhan, Hubei, China 430079

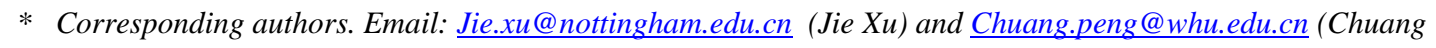 \\ Peng)
}

\begin{abstract}
Polyurethane (PU) is a commonly used insulation material for cold storage warehouses. The insulation performance of PU sandwich panels made from blended blowing agents were reassessed by k-factor measurements and insulation thickness calculation based on cold warehouse design standard, which has proved the significant impact of blowing agent difference on energy saving. The foam post-stability was also evaluated by mathematic profiling. The developed 3D paraboloid model based on gridding measurements has provided scientific method for panel shrinkage evaluation. Cell microstructure characterization and post-growth angle coefficients calculation were further performed for better understanding the shrinkage problem at microscopic level. The foaming process model of continuous panel production was developed based on FOAMAT characterization which has provided theoretical solution to panel processing.
\end{abstract}

\section{Keywords}

Polyurethane, cold warehouse, sandwich panel, insulation, shrinkage, microstructure, 


\section{Introduction}

Insulating materials with extremely low thermal conductivity $(<0.03 \mathrm{~W} / \mathrm{m} \cdot \mathrm{K})$ are commonly used for cold storage. Properly applied insulation helps in economic running of cold storage by considerable reduction of heat flow. Conventional insulating materials for cold warehouse are made based on the principle of cellular microstructure enclosed with air and blowing agents inside. The heat flow through cold surface is produced by vapour condensation over pressure gradient created by ambient air passing through the walls. This condensation is subject to cell gas freezing point and attributes to the materials conductivity.

The most frequently used commercial insulation materials are polystyrene foams including Expanded Polystyrene (EPS) and Extruded Polystyrene (XPS), and polyurethane foams including Polyurethane (PUR) and Polyisocyanurate (PIR). Nowadays, polyurethane foams generally outperform polystyrene foams to be the best insulating material choices for cold storage because of their better thermal conductivity (Fig. 1). Polyurethane foams (PUR and PIR) (Kuhn et al. 1992) are produced from exothermic reaction between polyisocyanate and polyols which creates copolymers with urethane repeat units and urea linkages when water presents. Because of high thermal stability of isocyanurate trimer structure from homocyclization of excessive isocyanates, PIR has the best fire resistance among all cellular foam materials, the fire risk of which is much lower than PUR and polystyrene foams in commercial applications (Chattopadhyay et al. 2009). 


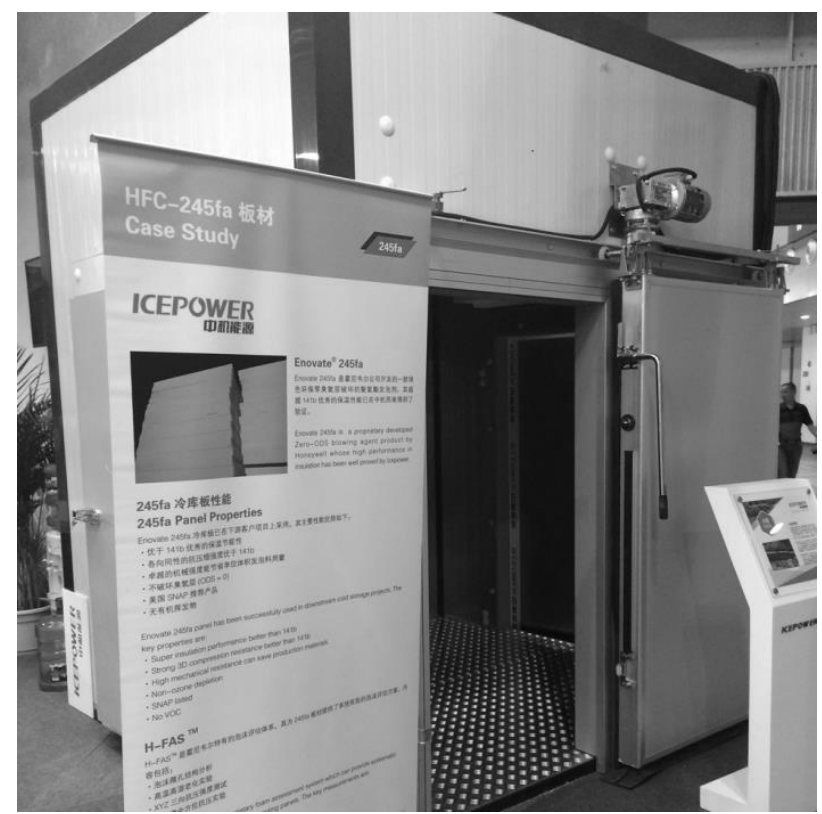

(a)

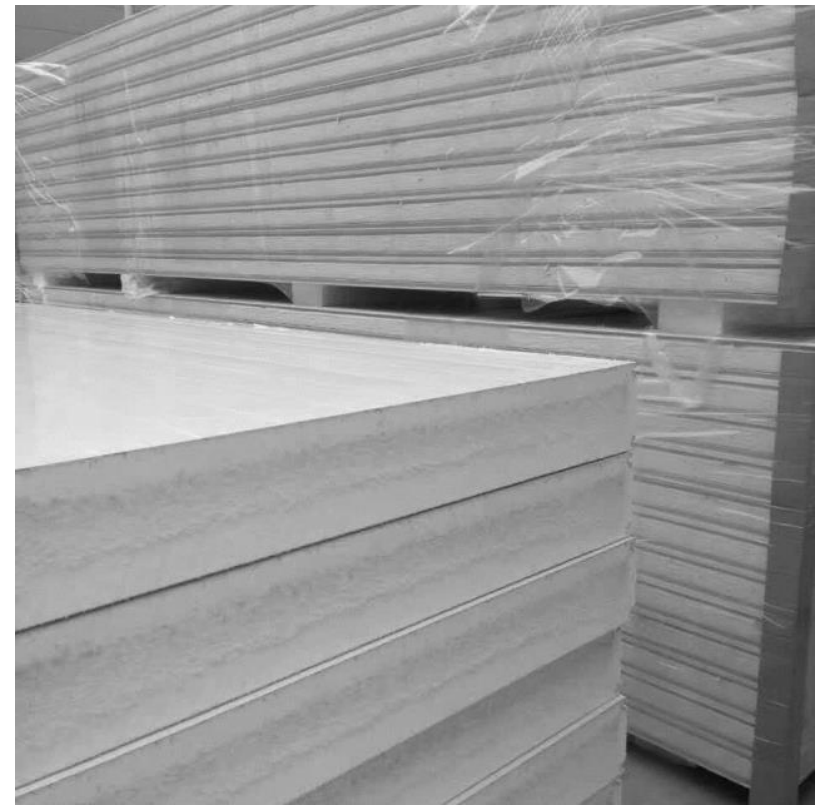

(b)

Fig. 1. High performance PIR panels for cold warehouse use made of HFC-245fa blowing

Thermal performance is one of the key properties for insulation material which can be measured in two different conditions: unsteady state and steady state. For unsteady state, thermal diffusivity $D$ is the parameter describing the dynamic propagation of thermal waves inside the media under both 
boundary conditions which is a derived quantity composed by intrinsic properties of thermal conductivity, density, and specific heat capacity. For steady state, the thermal performance is usually evaluated through thermal conductivity and thermal transmittance. Thermal conductivity $\lambda$, also known as k-factor, defines the steady state heat flow passing through a unit area of a homogeneous material, $1 \mathrm{~m}$ thick, induced by a $1 \mathrm{~K}$ difference of temperature on its faces, which is expressed in W/mK and can be measured in compliance with EN 12664 (low thermal resistance) (EN 12664. 2001), EN 12667 (high thermal resistance) (EN 12667. 2001), EN 12939 (thick products of high and medium thermal resistance) (EN 12939. 2000) and also ASTM C518 (ASTM C518-10). Thermal transmittance, also known as U-Value, defines steady state heat flow passing through a unit surface area induced by a $1 \mathrm{~K}$ difference of temperature which takes into account also the convective and radioactive heat transfers, which is expressed in $\mathrm{W} / \mathrm{m}^{2} \mathrm{~K}$ and can be measured with the hot-box method (EN ISO 8990; EN 12567-1; Asdrubali et al. 2011; Baldinelli et al. 2014) or calculated by ISO 6946 (ISO 6946). Nonetheless, the calculated U-values are usually lower than the measured ones (BRE No. 78132, 2000; Asdrubali et al. 2014).

As other cellular materials, the thermal conductivity of polyurethane foams is under effect of cell size (Wu et al. 1999) and cell gas. The gas generation driven by released heat from exothermal reaction is important part of foam formation. The cell gas in commercially produced foam mixes of gaseous physical blowing agents, carbon dioxide from water reaction with isocyanate, and fractional mole of air. Physical blowing agents including organofluorine, hydrocarbons, and liquid carbon dioxide are inertial and nonreactive to urethanization. The determining factor of blowing effectiveness as instinct vapour pressure effects in foaming differentiates blowing agents from nucleating agents. The thermophysical properties of organofluorine such as HFC-245fa, Solstice LBA are determined by its molecular structure. The structure symmetry and atom number of chloride and fluoride govern the volatility and immiscibility of organofluorine blowing agents.

Post-cure stability, a combination problem of post-expansion (inflation) and post-shrinkage (deflation), is one of the key performance measurements to polyurethane foam materials for cold storage warehouses use. Such foam volumetric changes start right after panels coming down from the production line and end when heat transfer over temperature gradient diminishing. This 
inflation-deflation instability is usually characterized by progressive dimensional measurements over time at numerous points on foam surface. Great amount of measurements can produce better reproducibility and preciseness. When deflation extensively outperforms inflation in some cases, the damage scale escalates resulting in corresponding proportion problem in construction. Thus panel post-stability control is critical to cold warehouse building quality management.

Polyurethane foam insulation panels for cold storage use are usually produced by continuous line processing or multilayer pressing production. The foaming kinetics of urethanization has been well studied by integrating chemical curing reaction with physical blowing process (Baser et al. 1994; Baser et al. 1994; Haberstroh et al. 2004; Seo et al. 2005; Mao et al. 2005; Geier et al. 2009; Bikard et al. 2005; Bikard et al. 2007). The entire foaming process can be characterized by FOAMAT reactivity profiling (Patent No. 3621819 and 19730891) through progressive monitoring of liquid-gas equilibrium in vaporization and Newton rheological flow in polymerization. Characterizing foaming of industrial processing has also been successfully made in some commercial cases. For instance, Baser and Kharkhar developed kinetic models (Baser et al. 1994; Baser et al. 1994) were further extended to be used to predict three-dimensional foam expansion in producing refrigerator cavity (Seo et al. 2005). Bikard et al. (Bikard et al. 2007) also developed reduced order foaming kinetic model directly from the continuity equation using threedimension space-time finite element method, which well fitted into industrial application case of car seat production.

In this study, the thermal conductivity and post-stability of polyurethane foams were re-evaluated in mathematic ways. The cold storage warehouse design standard was employed to calculate the insulation performance gap between standard recommended thermal conductivity and experimentally measured value based on blowing agents difference. The foam post-stability was characterized by gridding measurements and SEM observation. The inflation-deflation model was developed based on 3D displacement measurements over time. Furthermore, the polyurethane panel foaming process of continuous line production was theoretically modelled to better understand the cold warehouse panels' production. 


\section{Experiments and methods}

\section{Insulation performance}

The insulation performance tests were conducted in Honeywell Shanghai Lab. Pre-blended polyols (for panels with flammability class B1 GB8624-97) and isocyanates (p-MDI polymeric methyldiisocyanate) were supplied by Bayer China. The tertiary amine catalysts (cyclohexylamine) for blowing and metal catalysts (potassium octanoate) for gelling were included in pre-blended polyols together with surfactants (polydimethylsiloxane). In order to better manage the foaming process and mitigate possible vaporization during transportation, the blowing agent blends (HCFC-141b/HFC-245fa) were added in addition based on parts by weight (pbw). Six formulations with different alternating amount of blowing agents blends were made for tests starting from baseline 100\% pure HCFC-141b (23 pbw) with 0\% HFC-245fa till 0\% HCFC-141b with $100 \%$ HFC-245fa with $20 \%$ weight increase for each. The materials reactivity (cream time CT, gel time GT, and tack free time TFT) were measured sequentially on the same samples with milkshake cup rise. The free rise density FRD were measured according to polyurethane foam cup test ASTM D7487-2008.

Table 1. Test panel formulations with blowing agent blends

\begin{tabular}{lcccccc}
\hline & $1 \#$ & $2 \#$ & $3 \#$ & $4 \#$ & $5 \#$ & $6 \#$ \\
\hline Polyols at 20 ${ }^{\circ} \mathrm{C}$ & 100 & 100 & 100 & 100 & 100 & 100 \\
HCFC-141b & 23.0 & 18.4 & 13.8 & 9.2 & 4.6 & 0 \\
HFC-245fa & 0 & 5.2 & 10.5 & 15.7 & 21.0 & 26.2 \\
p-MDI at 20 ${ }^{\circ} \mathrm{C}$ & 203 & 203 & 203 & 203 & 203 & 203 \\
Total pbw (g) & 326 & 327 & 327 & 328 & 329 & 329 \\
Cream Time (CT) (s) & 21 & 20 & 20 & 18 & 17 & 16 \\
Gel Time (GT) (s) & 52 & 61 & 64 & 67 & 70 & 71 \\
Tack Free Time (TFT) & 71 & 85 & 89 & 88 & 105 & 103 \\
$(\mathrm{~s})$ & & & & & & \\
Free Rise Density & 39.2 & 39.3 & 38.9 & 39.6 & 38.7 & 39.8 \\
$\left(\right.$ FRD) $\left(\mathrm{kg} / \mathrm{m}^{3}\right)$ & & & &
\end{tabular}


The thermal conductivity measurements were conducted at EKO Low Temperature Conductivity Instrument with sample size range $8 \times 8 \times(1 \sim 4)$ inches, measurement range $0.005 \sim 0.8 \mathrm{~W} / \mathrm{m} \cdot \mathrm{K}$, and working temperature range $-165 \sim 20{ }^{\circ} \mathrm{C}$. The measuring temperature difference between the upper and lower plates is $20^{\circ} \mathrm{C}$. To fit into the working temperature range of cold warehouse, the foam samples were evaluated at temperature from $-50{ }^{\circ} \mathrm{C}$ to $10{ }^{\circ} \mathrm{C}$. The same measurements were conducted on aged samples. The accelerated aging treatments were taken at $70{ }^{\circ} \mathrm{C}$ (upper temperature) and $-30{ }^{\circ} \mathrm{C}$ (lower temperature) over $48 \mathrm{hrs}$ in a temperature/humidity recycling chamber (working range: temperature $-60 \sim+190^{\circ} \mathrm{C}$ and humidity $<95 \%$ ).

To further evaluate the impact on insulation layer thickness design by using foam materials with improved k-factor by high performance blowing agents, China Code for Design of Cold Store (GB 50072. 2010) was employed for theoretical calculation. The thicknesses were calculated based on different standard defined building parts (roof/external wall, partition wall, partition floor, ground floor, and suspending floor) and then further compared with standard recommended polyurethane thermal conductivity value $(0.024 \mathrm{~W} / \mathrm{m} \cdot \mathrm{K})$.

\section{Post-stability}

The rigid PIR foam sample panels made of HCFC-141b/HFC-245fa blends were produced at Honeywell customer site (Table 2). The polyol blend was supplied by BASF, all ingredients were included except blowing agents. The blowing agents (HCFC-141b and HFC-245fa) were added in separate feedstock tanks and mixed with polyols by system cycling. CT and GT were checked before field trials to ensure the material quality. Additional catalyst feedstock for foaming reaction (GT) was employed to adjust the foam rise and match the material reactivity to production line speed. Two in-place density $43 \mathrm{~kg} / \mathrm{m}^{3}$ and $40.5 \mathrm{~kg} / \mathrm{m}^{3}$ were made on purpose for evaluating overpacking effect. The production line is 6 packs Hennecke PU panel continuous line with line speed setting $3.00 \mathrm{~m} / \mathrm{min}$ and gun speed setting $282.91 \mathrm{~g} / \mathrm{min}$. The panel specification is $650 \times 110 \times 20 \mathrm{~cm}$. Foam specimen collection started from position $>100 \mathrm{~m}$ on length to ensure foam quality. 
Table 2. Formulation for continuous PIR panels production

\begin{tabular}{ll}
\hline Components & Formulation $(\mathrm{pbw})$ \\
\hline Polyols at $20^{\circ} \mathrm{C}$ & 100.00 \\
p-MDI at $20^{\circ} \mathrm{C}$ & 169.60 \\
Catalyst & 1.82 \\
$\mathrm{HCFC}-141 \mathrm{~b}$ & 7.99 \\
$\mathrm{HFC}-245 \mathrm{fa}$ & 3.50 \\
Cream Time (CT) (s) & $7-8$ \\
Gel Time (GT) (s) & 56 \\
\hline
\end{tabular}

The foam samples were cut from the sample panels for further measurements. 3D Cartesian coordinate was set with line running direction (X-axis), panel width (Y-axis) and panel thickness (Z-axis). All dimensional measurements are conducted on YZ plane $(110 \times 20 \mathrm{~cm})$ by equal grids. The delimiting lines were labelled L1/L2/L3/C/R3/R2/R1 (Y-axis) and T1/T/2/C/B2/B1 (Z-axis). The Z-axis shrinkages were measured on intersections using digital Vernier Calipers (range $20 \mathrm{~cm}$ and precision $0.01 \mathrm{~mm}$ ) with frequency each $24 \mathrm{hrs}$ for 4 days. The foams of both densities were measured. All data were analysed by statistics software MINITAB 16 and 3D elliptic paraboloid profiles were built accordingly. The panel inflation-deflation model was developed within the boundary of panel size $200 \times 1100 \mathrm{~mm}^{2}$ from displacement calculation on 2D parabolic functions with distance a across major axis $\mathrm{b}$ (X-Z plane) and distance $\mathrm{b}$ across minor axis a (Y-Z plane) respectively. The shrinkage progresses were evaluated by modelling coefficients. Gaussian curvatures were calculated to further understand the graphic deformation.

Some foam samples (in-place density $40.5 \mathrm{~kg} / \mathrm{m}^{3}$ ) were taken to freezing tests in cooling tank at $30^{\circ} \mathrm{C}$ for $24 \mathrm{hrs}$. The microstructure measurements before and after cooling were performed using scanning electron microscope (SEM, Hitachi SU 8200). The axisymmetric dimension, strut length 1 , strut thickness $t_{e}$, and face thickness $t_{f}$ of each cell, within the observation scope, were measured by en suite equipped scales. All images were documented for crosschecking and further measurements. The sophistication of specimen lamination, and optical focal adjustment, allow for great access to cell structure. The degree of anisotropy of each cell was calculated by dividing its maximum height (along the y-axis) by its orthogonal maximum length (along the $\mathrm{x}$-axis). The 
mean value of both measurements was approximated as the cell's diameter. The statistical normality analysis were conducted using the MINITAB 16 software.

\section{Blowing and foaming process}

The blowing agent effectiveness was defined by FOAMAT reactivity profiles. The formulation differences by blowing agents (HCFC-141b and HFC-245fa) were evidently observed in free foam rise measurements. The productivity optimizations were also characterized by FOAMAT on blowing effect, catalyzation, line speed changes. The foam processing was theoretically modelled by vector analysis of vertical foam rise and horizontal line running. The unit cell growth is characterized by degree of cell anisotropy calculated based on 2D structural deformation induced by blowing and line moving.

\section{Results and discussion}

\section{Insulation performance}

\section{Thermal conductivity measurements}

Thermal insulation is commonly represented by R-value which is expressed as the thickness of the materials normalized to thermal conductivity. The polyurethane foam thermal conductivity is superposition of three heat transfer modes (Jarfelt et al. 2006): solid polymer conduction, cell gas convection, and cell wall radiation.

$$
\lambda_{\text {total }}=\lambda_{\text {polymer } / \text { conduction }}+\lambda_{\text {gas } / \text { convection }}+\lambda_{\text {wall/radiation }}
$$

In construction thermal calculation, the materials insulation narrows down to single sense of polymer solid conduction of cell skeleton structure plus cellular gas convection of cell gases. The reflective insulation of microstructure windows is usually neglectable and not taken into account. In most cases, the thermal insulation of cold warehouse only refers to insulation barrier materials employed to retard heat transfer. For polyurethane foams, the cellular gas convection accounts dominantly for over $60 \%$ of total thermal conductivity. The mixing ratio, 
vapor pressure, and diffusion rate of cell gases can manipulate the foam thermal conductivity and further impact on the materials insulation.

Usually the polyurethane cell gases are a gaseous mixture of vaporized blowing agents, produced carbon dioxide, and inbound diffused air. The cells nucleate at random Voronoi site driven by blowing agents vaporization, sometimes with auxiliary support from nucleating agents, and then coarsen under partial pressure, propagate by exclusion competition, coalescence under surface energy manipulation, till the end of interface equilibrium constrained by solidification. The blowing progress continues consistently with carbon dioxide release and blowing agents vaporization. The increasing volume of carbon dioxide and gaseous blowing agent governs growth of foam porosity and solid fractions. When gas expansion prolongs after gelation, the negative cells opening growth resulting from lower surface energy in liquid phase starts and the cell structures are under damaging effect by vapour pressure but the degree of crosslink may provide structural support against cell collapse (Monteavaro et al. 2005). More closed cells may survive on the other scenario when gas formation completes earlier than gelation (Guo et al. 2000).

Many research efforts have been invested in developing blowing agents with low conductivity and controllable high vapor pressure. Besides environmental concerns, blowing agents with low boiling point (HFC-245fa) become more favourable than the blowing agents with high boiling point (HCFC-141b) for productivity consideration regardless of the cost efficiency. The blend formulations with these two exhibit more economic and scientific significances. In this study, the thermal conductivities of polyurethane foams with blended blowing agents at low working temperatures of cold warehouses were measured (Fig.2). 


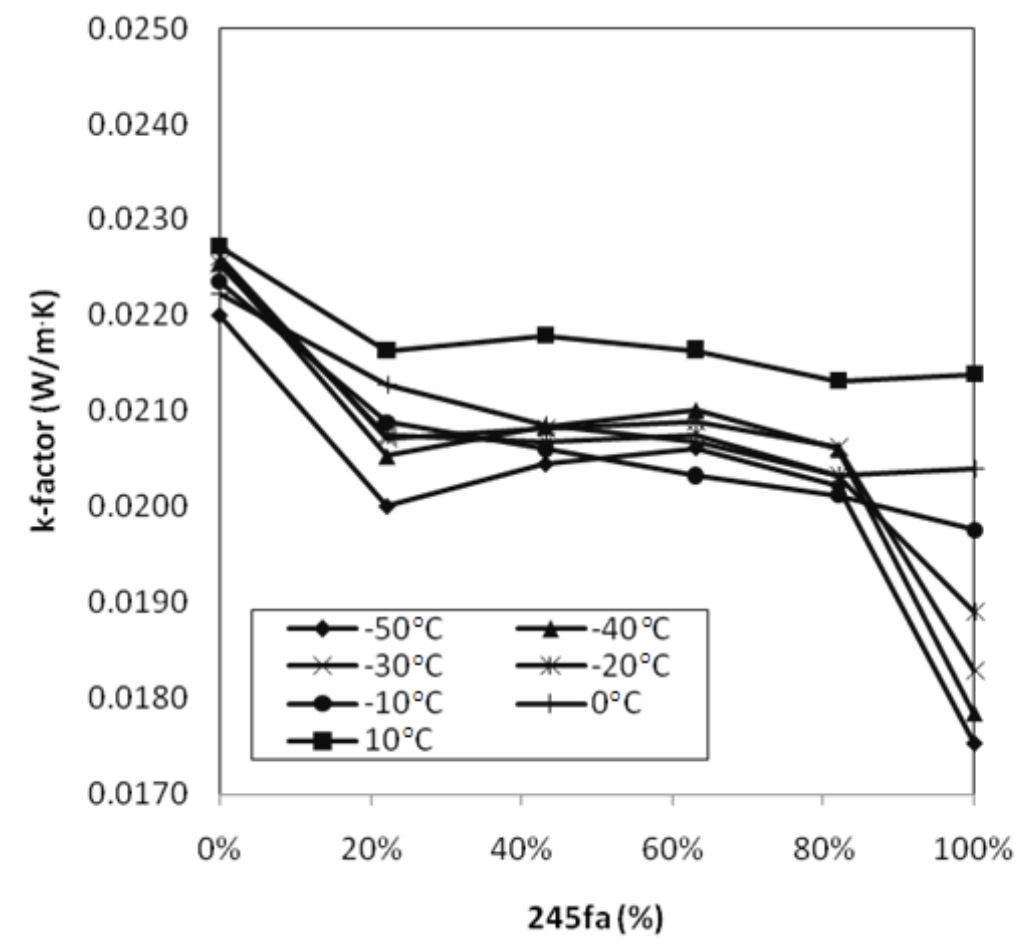

(a)

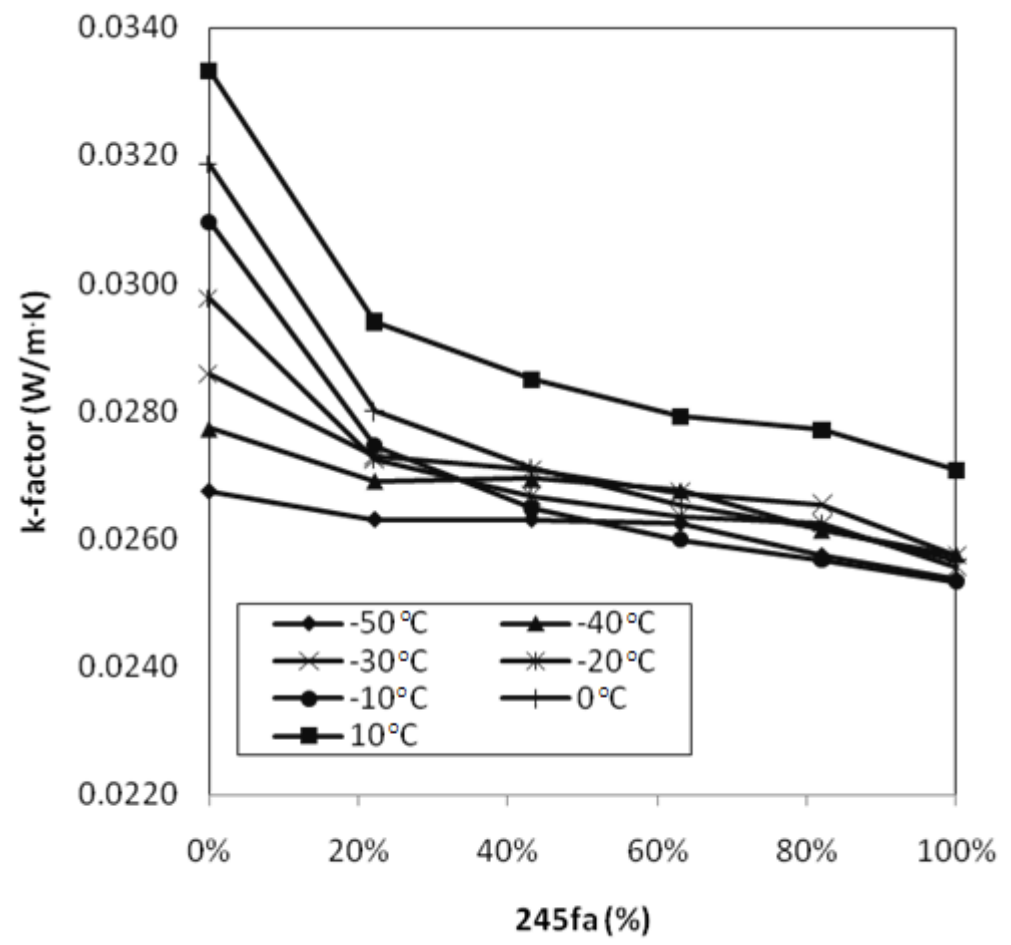

(b)

Fig. 2. k-factor measurements of HCFC-141b/HFC-245fa blends polyurethane (a) asprepared (b) aged 
Both measured thermal conductivity before and after aging treatment present downward trends with increasing HFC-245fa ratio which suggests the insulation performance of polyurethane foam can be improved by adding more blowing agents with low boiling point such as HFC-245fa. Furthermore, the thermal conductivity performance before aging presents even increasingly lower values at temperatures below zero degree $\left(-20 /-30 /-40 /-50{ }^{\circ} \mathrm{C}\right)(\mathrm{Fig} 2 \mathrm{a})$ which reflects HFC-245fa has even better insulation performance at freezing temperature which is the best choice for cold warehouse use. Nonetheless, this advantage over HCFC-141b is impaired after aging as the measured thermal conductivities with more HFC-245fa increase faster than those with less HFC245fa (Fig 2b). In other words, foams with more HFC-245fa experience more insulation erosion in heating and cooling cyclic treatments. This is probably because high diffusion rate of HFC245 fa intensifies outbound mass flow resulting in more insulating gas loss. The damage scale is under effect by blend ratios of two blowing agents.

\section{Insulation thickness calculation}

To further understand the blowing agents' effect on cold warehouse insulation, k-factor values at specific working temperature range of cold warehouse in different regions need to be investigated. The maximum temperatures in history of all China provinces and working temperature range for various types of cooling warehouses were collected (Fig 3 and Fig 4). The mean temperatures between these two were calculated to derive the determining temperature range for k-factor. The upper limit was calculated by mean value of highest provincial maximum temperature and lowest cold warehouse working temperature; the lower limit was calculated by mean value of lowest provincial maximum temperature and highest cold warehouse working temperature. The obtained temperature range is $0.75 \sim 30.25^{\circ} \mathrm{C}$ as calculated. Then k-factors defined in this range were calculated from correlation results of experimental measured values. The obtained k-factor values were presented against standard recommended value $(0.024 \mathrm{~W} / \mathrm{m} \cdot \mathrm{K})$ (Fig 5). Substantial gap between these two indicates polyurethane panels made from HCFC-141b/HFC-245fa blowing 
agents have much lower k-factor than theoretically recommended polyurethane k-factor $(0.024 \mathrm{~W} / \mathrm{m} \cdot \mathrm{K})$

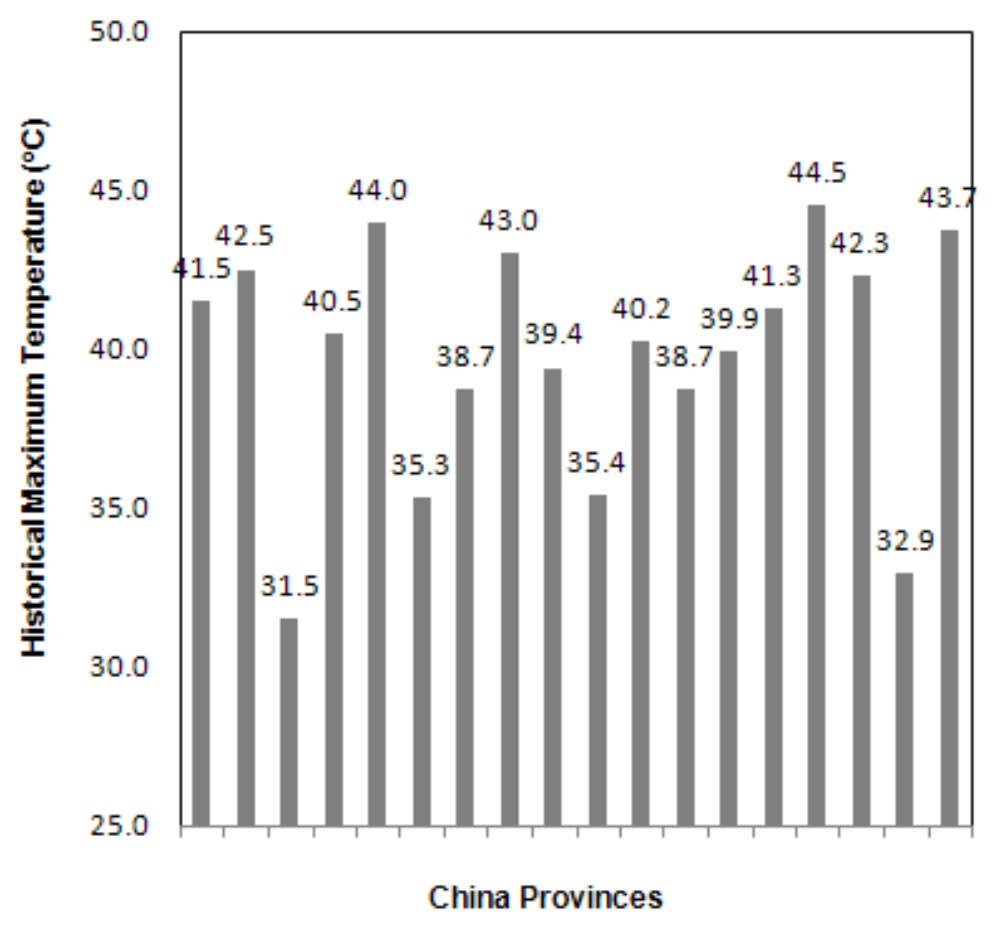

Fig. 3. Historical maximum temperature of all China provinces 


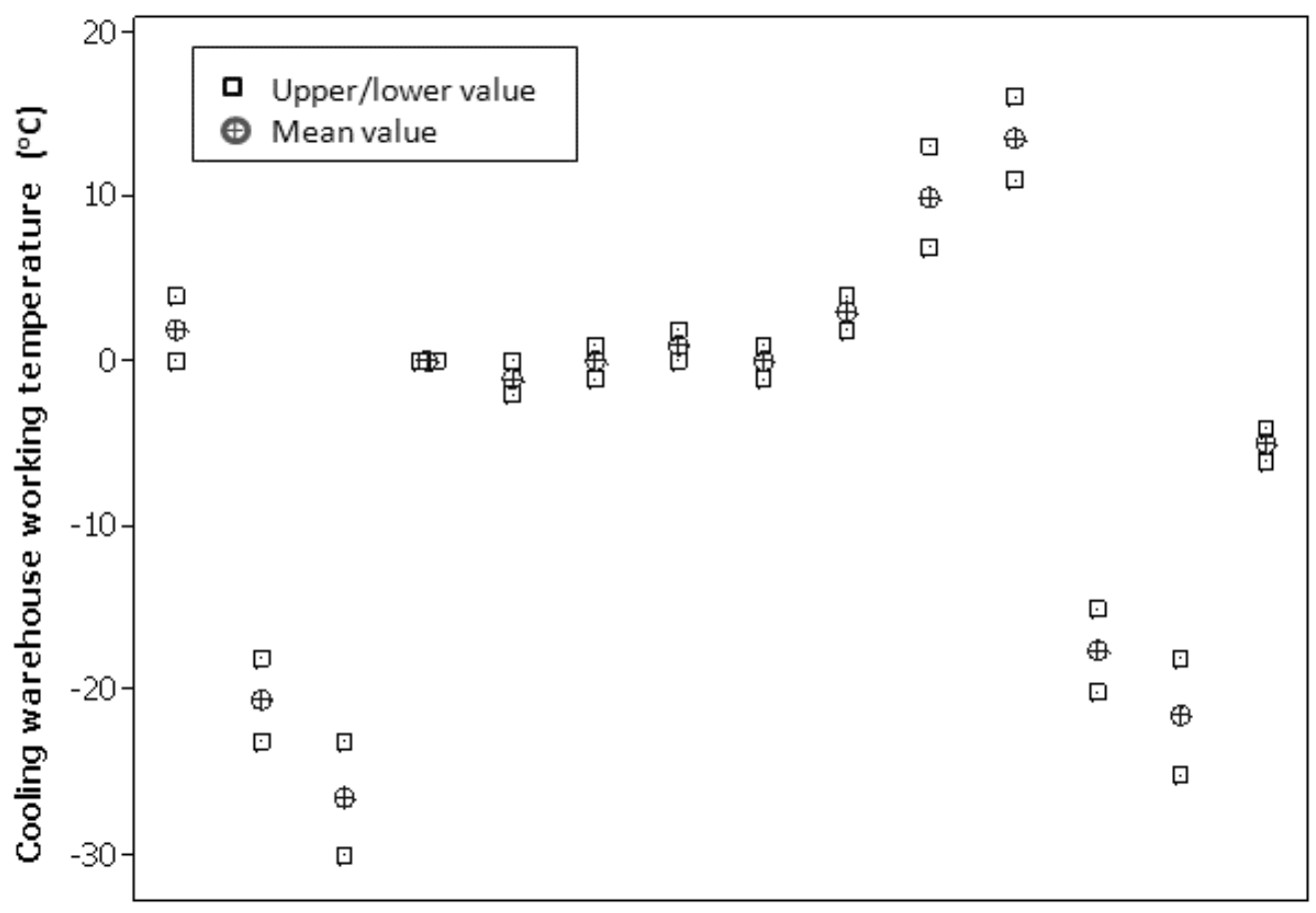

Fig. 4. Generic working temperatures for cold storage warehouses

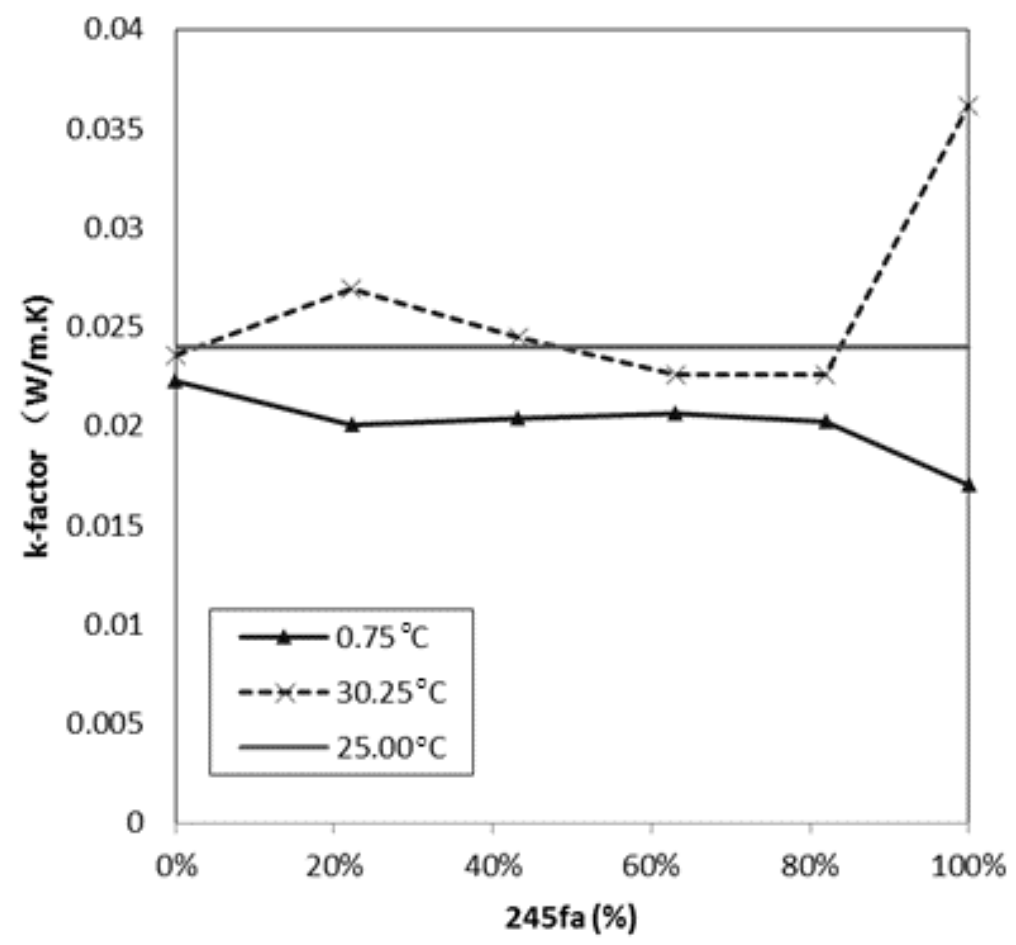

Fig. 5. Comparison of actual and standard recommended k-factors before calibration 
According to China Code for Design of Cold Store (GB 50072. 2010), the insulation barrier of cold warehouse is defined as bulk materials with single- or multi- insulation layers. The complete thickness formula containing insulation layers and interior/exterior wall structures is as below:

$$
\mathrm{L}=\mathrm{k}\left[\mathrm{R}_{0}-\left(\frac{1}{\mathrm{~h}_{\mathrm{e}}}+\frac{\mathrm{L}_{1}}{\mathrm{k}_{1}}+\frac{\mathrm{L}_{2}}{\mathrm{k}_{2}}+\cdots+\frac{\mathrm{L}_{\mathrm{n}}}{\mathrm{k}_{\mathrm{n}}}+\frac{1}{\mathrm{~h}_{\mathrm{i}}}\right)\right]
$$

Where $\mathrm{L}$ denotes overall insulation barrier thickness, $\mathrm{k}$ denotes insulation material thermal conductivity, $R_{0}$ denotes wall structure thermal resistance, $h_{e}$ and $h_{i}$ represent heat transfer coefficient of interior and exterior wall, respectively. $L_{1}, L_{2}, L_{n}$ represent thickness of each insulation layer and $\mathrm{k}_{1}, \mathrm{k}_{2}, \mathrm{k}_{\mathrm{n}}$ represent thermal conductivity of each insulation layer respectively. To differentiate the insulation performance at different part of the cold warehouse, the standard specifies the building sectors into roof/wall, partition board, partition floor, and suspending floor. Both thermal resistance of wall structure $R_{0}$ and heat transfer coefficients of interior and exterior walls $h_{i}$ and $h_{e}$ can be collected from material reference table in standard.

In case of movable modular cold warehouse, different from multilayer walling insulation, the wall panel is made of single layer insulation barrier, namely sandwich polyurethane panel with neglectable metal face thickness ( $\sim 0.6 \mathrm{~mm}$ metal). Thus, the insulation thickness formula then can be simplified into:

$$
\mathrm{L}=\mathrm{k}\left[\mathrm{R}_{0}-\left(\frac{1}{\mathrm{~h}_{\mathrm{e}}}-\frac{1}{\mathrm{~h}_{\mathrm{i}}}\right)\right]
$$

With different determining temperature, the thermal resistances and heat transfer coefficients of all building sectors were collected and consolidated in Table 3. The heat transfer coefficients of exterior wall $h_{e}$ and interior wall $h_{i}$ were specified by defined temperatures ranging at 8 29 $\mathrm{W} / \mathrm{m}^{2} .{ }^{\circ} \mathrm{C}$. To simplify the calculation, the determining temperature for $\mathrm{k}$-factor set at $10{ }^{\circ} \mathrm{C}$, which is the most common mean temperature value for cold warehouse use. Both assigned working 
temperatures and k-factor values were calibrated by calibration coefficients defined by standard $\mathrm{a}=1$ and $\mathrm{b}=1.4$ for polyurethane foams respectively.

Table 3. Structure thermal resistance for calculation

\begin{tabular}{|c|c|c|c|c|c|c|}
\hline & \multicolumn{2}{|c|}{$\begin{array}{l}\text { Temperature difference } \\
\qquad\left({ }^{\circ} \mathrm{C}\right)\end{array}$} & \multicolumn{2}{|c|}{$\begin{array}{l}\text { Thermal resistance } \\
\qquad\left(\mathrm{m}^{2} \cdot{ }^{\circ} \mathrm{C} / \mathrm{W}\right)\end{array}$} & \multicolumn{2}{|c|}{$\begin{array}{l}\text { Heat transfer } \\
\text { coefficient } \\
\left(\mathrm{W} / \mathrm{m}^{2} .^{\circ} \mathrm{C}\right)\end{array}$} \\
\hline & Lower & Upper & Lower & Upper & $h_{e}{ }^{c}$ & $\mathrm{~h}_{\mathrm{i}}^{\mathrm{c}}$ \\
\hline Roof/External wall & $15.5^{\mathrm{a}}$ & $74.5^{\mathrm{a}}$ & 6.99 & 11.01 & 23 & 29 \\
\hline Partition wall & 18.0 & 27.0 & 5.45 & 12.00 & 29 & 29 \\
\hline Partition floor & 5.0 & 35.0 & 1.89 & 4.77 & 12 & 12 \\
\hline Ground floor & $31.5^{\mathrm{b}}$ & $79.5^{b}$ & 1.72 & 4.77 & 8 & 12 \\
\hline Suspending floor & $31.5^{\mathrm{b}}$ & $79.5^{\mathrm{b}}$ & 2.15 & 4.77 & 8 & 8 \\
\hline
\end{tabular}

Notes: ${ }^{a}$ the calculated temperature difference is approximated to standard range $20 \sim 80{ }^{\circ} \mathrm{C}$.

${ }^{\mathrm{b}}$ the external temperature for calculation is assumed as historical maximum temperature

${ }^{c}$ the external and internal heat transfer coefficients decided on cooling sector scenarios

All calculation results from measured k-factor values of HCFC-141b/HFC-245fa blends foams (grey bars) and standard recommended values $(24 \mathrm{~mW} / \mathrm{m} \cdot \mathrm{K})$ (black) were presented in Fig 6.

The considerable differences between these two were observed as the values derived from measured data are much lower than those from recommended data for all defined sectors, which suggests HCFC-141b/HFC-245fa blends can make difference on insulation thickness calculation for cold warehouse design. The standard recommended thermal conductivity value for polyurethane $(0.024 \mathrm{~W} / \mathrm{m} \cdot \mathrm{K})$ may not be suitable for cold warehouse insulation thickness calculation and considerable deviation can be produced in design calculation if the panels used were made of HCFC-141b/HFC-245fa blends 

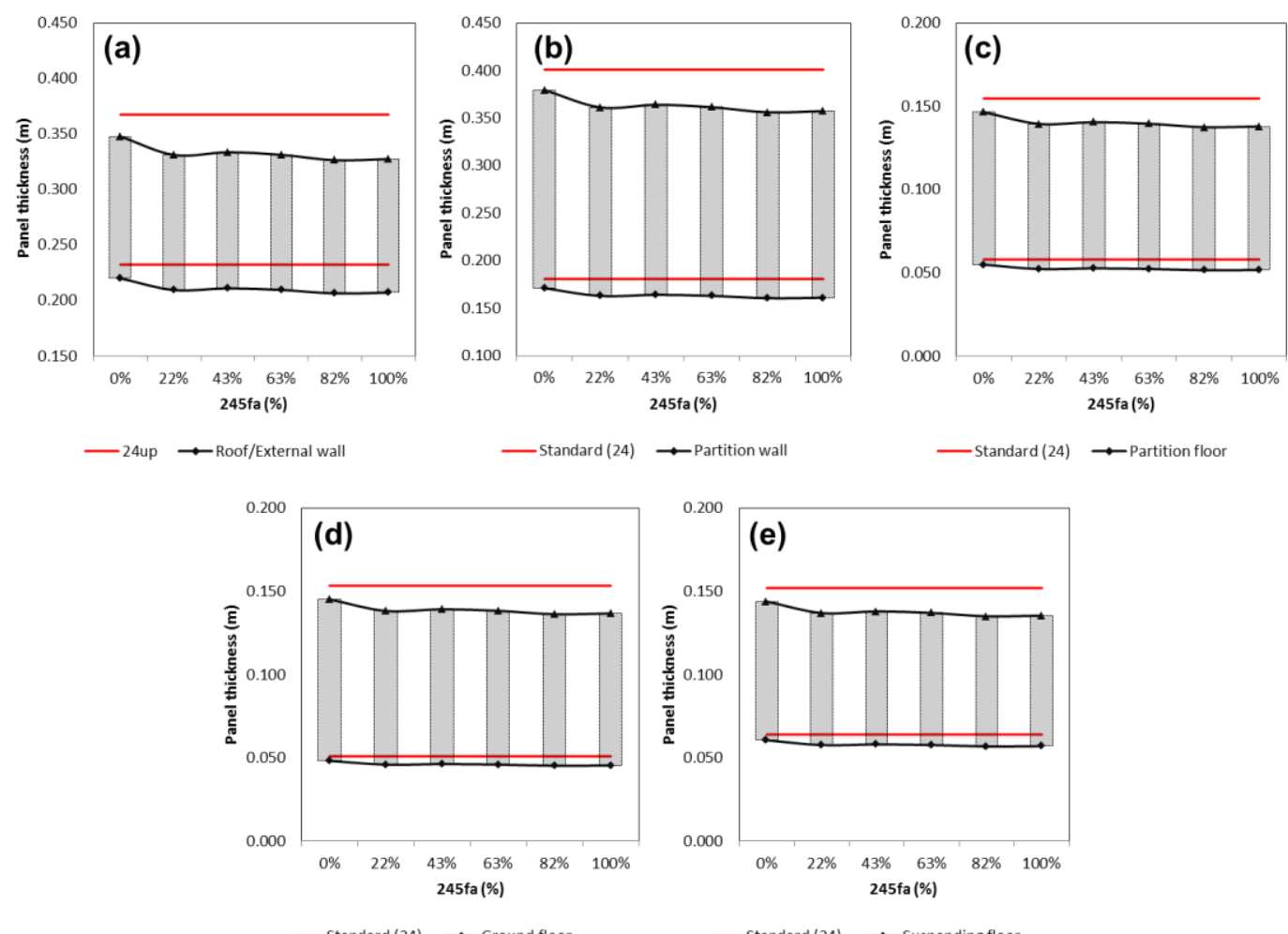

—Standard (24) $\rightarrow$ Ground floor

$\longrightarrow$ Standard (24) $\rightarrow$-Suspending floor

Fig. 6. Insulation panel thickness calculations for HCFC-141b/HFC-245fa blends (a)

Roof/external wall (b) Partition wall (c) Partition floor (d) Ground floor (e) Suspending floor

\section{Post-stability}

\section{D paraboloid model}

In panel production, when the curing process ends at Tack Free Time (TFT), heat transfer over temperature gradient starts and the free energy equilibrium breaks down, resulting in fast foam temperature decrease, which leads to possible dimensional changes due to limited crosslink degree and low density. The cell microstructures stabilize again at geometric equivalence when temperature re-balanced at equilibrium. This process is defined as volumetric change with geometric inflation and deflation. The immediate inflation is possible for polyurethane foams produced from blowing agents with low boiling point and high vapour pressure. The sever shrinkage may occur for foams with low crosslink produced by polyols with low functionality. 
Overpacking as an effective solution may be able to partially solve the instability problem by improving solid fraction and reducing foam porosity. Other solutions include more branched crosslink by higher functionality polyols, higher density to increase stiffness and hardness, and longer cure time to achieve heat equilibrium. The instability dynamics can be studied by long time measurements over storage which can be characterized by simple formula as:

$$
\begin{gathered}
D+\left(L_{i}-L_{d}\right)=D^{\prime} \\
\Delta D=D^{\prime}-D=L_{i}-L_{d}
\end{gathered}
$$

Where $D$ and $D^{\prime}$ denote foam initial and final dimensions respectively, $\Delta \mathrm{D}$ denotes post-cure dimensional change, $L_{i}$ represents inflation and $L_{d}$ represents deflation.

3D post-stability visualization can be effective method to present inflation-deflation changes. In this study, the dimensional changes on panel surface over storage time were measured on panel cross-section perpendicular to line moving direction using gridding method. All data collected during four measuring days were consolidated and presented in 3D Cartesian coordinate (Fig 7). All obtained 3D profiles displayed in easily identified elliptic paraboloid shape with downward open on Y-Z plane with calculable rising curvature in time pace. 
(a)

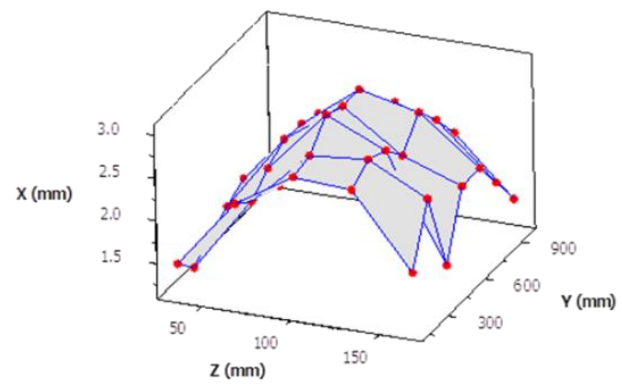

(c)

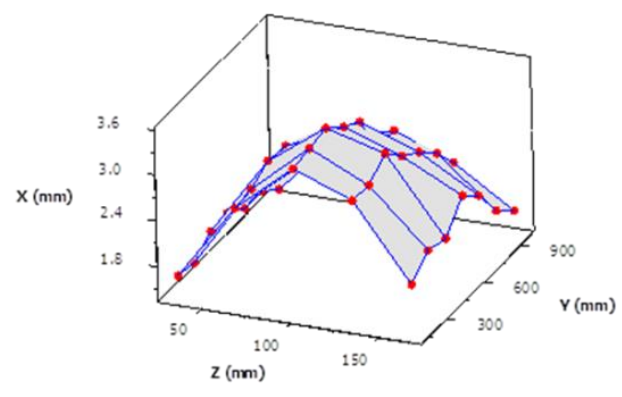

(b)

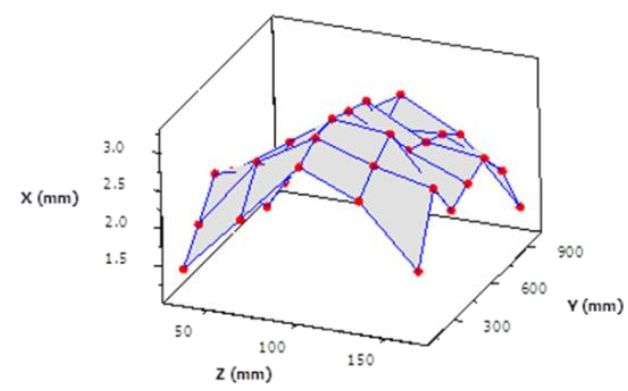

(d)

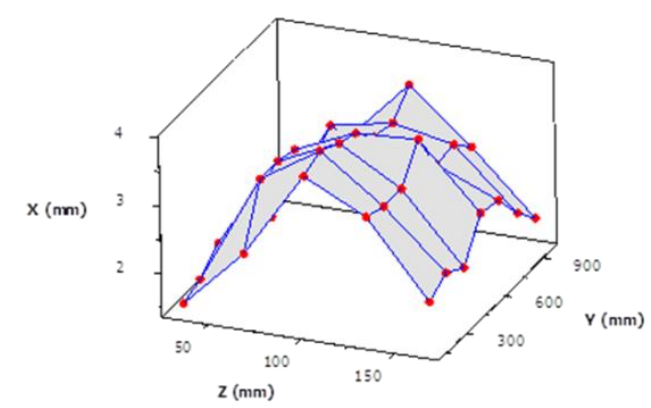

Fig. 7. 3D shrinkage visualizations of Y-Z plane on PIR foam panels (in-placement density $40.5 \mathrm{~kg} / \mathrm{m3}$ ) (a) Day 1 (b) Day 2 (c) Day 3 (d) Day 4

Paraboloid is a quadric surface of special kind. The post-growth paraboloid is an elliptic paraboloid shaped as an oval cup which can be defined in properly set 3D Cartesian coordinate with major and minor axis at bottom and vertical axis through vertex. As defined in coordinate system, the paraboloid function can be written into (Thomas et al. 2005).

$$
\frac{z}{c}=\frac{x^{2}}{a^{2}}+\frac{y^{2}}{b^{2}}
$$

Where $a$ and $b$ are the major and minor distances of the flat elliptic bottom, $c$ is the height from vertex to bottom centroid. Thus 2D parabolic functions on cross-section cutting through major or minor axes can be further written as:

$$
\begin{aligned}
& \frac{z-\gamma}{c}=-\frac{1}{a^{2}}(x-\alpha)^{2} \\
& \frac{z-\gamma}{c}=-\frac{1}{b^{2}}(y-\beta)^{2}
\end{aligned}
$$


Where the coordinate was built at the centroid $C(\alpha, \beta, \gamma)$. Both of these two 2D parabolic functions cut through vertex point $V\left(\frac{b}{2 a}, \frac{b^{2}-4 a c}{4 a}\right)$. The featured paraboloid may be able to transform into circular paraboloid in case of infinite free rise foam without boundary when $a=b$. In that case, the surface function can be written:

$$
\frac{z}{c}=\frac{x^{2}+y^{2}}{a^{2}}
$$

The 2D parabolic functions were further evaluated under consideration of panel dimensions. The quadratic equations were converted by square completion:

$$
Y=a\left(X-\frac{b}{2 a}\right)^{2}-\frac{b^{2}-4 a c}{4 a}
$$

The paraboloid vertex of each measurement was redefined by parabolic coefficients:

$$
C\left(\frac{L_{z}}{2}, \frac{L_{y}}{2}, 0\right)
$$

Where $L_{z}$ and $L_{y}$ are dimensions of panel thickness (Z-axis) and width (Y-axis). Thus, two 2D parabolic functions were rewritten as:

$$
\begin{aligned}
& \frac{x-c}{c}=-\frac{1}{a^{2}}\left(z-\frac{L_{z}}{2}\right)^{2} \\
& \frac{x-c}{c}=-\frac{1}{b^{2}}\left(y-\frac{L_{y}}{2}\right)^{2}
\end{aligned}
$$

Then further evaluations give:

$$
\begin{aligned}
& x=-\frac{c}{a^{2}}\left(z-\frac{L_{z}}{2}\right)^{2}+c \\
& x=-\frac{c}{b^{2}}\left(y-\frac{L_{y}}{2}\right)^{2}+c
\end{aligned}
$$

Then, further replace paroboloid coefficient $c$ with shrinkage degree coefficient $S$ defined by maximum deflation in center characterized by distance maximization between origin centroid and vertex, and then combine two 2D parabolic functions to give 3D paraboliod model: 


$$
\frac{x-S}{S}=\frac{\left(z-\frac{L_{z}}{2}\right)^{2}}{a^{2}}+\frac{\left(y-\frac{L_{y}}{2}\right)^{2}}{b^{2}}
$$

Meanwhile, the mathematic surface curvature can be used to further characterize deflation degree. Gaussian curvature is one of the most effective and manageable definition being used, which is given by

$$
K=\frac{f_{x x} f_{y y}-f_{x y} f_{y x}}{\left(1+f_{x}^{2}+f_{y}^{2}\right)^{2}}
$$

Where $K$ is the determinant of the Hessian matrix of $f$ and the scaled measure of the surface concavity. The featured paraboloid grows towards deeper curvature over shrinking. Each calculated parabolic factor can give indication of processing variability and foam heterogeneousness.

3D paraboliod model was then rewritten into the form for curvature calculation as follows:

$$
x=\frac{s}{a^{2}} z^{2}+\frac{s}{b^{2}} y^{2}-\frac{s}{a^{2}} L_{z} z-\frac{s}{b^{2}} L_{y} y+\frac{s}{a^{2}}\left(\frac{L_{z}}{2}\right)^{2}+\frac{s}{b^{2}}\left(\frac{L_{y}}{2}\right)^{2}+S
$$

Then Gaussian curvature function becomes:

$$
K=\frac{f_{z z} f_{y y}-f_{z y} f_{y z}}{\left(1+f_{z}^{2}+f_{y}^{2}\right)^{2}}=\frac{\frac{2 S 2 S}{a^{2} b^{2}}}{\left(1+\left(\frac{2 S}{a^{2}}\right)^{2}+\left(\frac{2 S}{b^{2}}\right)^{2}\right)^{2}}=\frac{4 S^{2}}{a^{2} b^{2}\left(1+\frac{4 S^{2}}{a^{4}} z^{2}+\frac{4 S^{2}}{b^{4}} y^{2}\right)^{2}}
$$

The curvature values of four days data through modeling were calculated (Fig. 8) and statistically analyzed by MINITAB 16 (Table 4). The obtained curvatures show extensive shrinkage damages with different extensions at vertex stretching and bottom expanding, which suggests worse extensive surface damage progress on width (YZ plane) than center which is constrained by panel size boundary. The extensiveness can be escalating infinitely under ideal unbounded condition. 


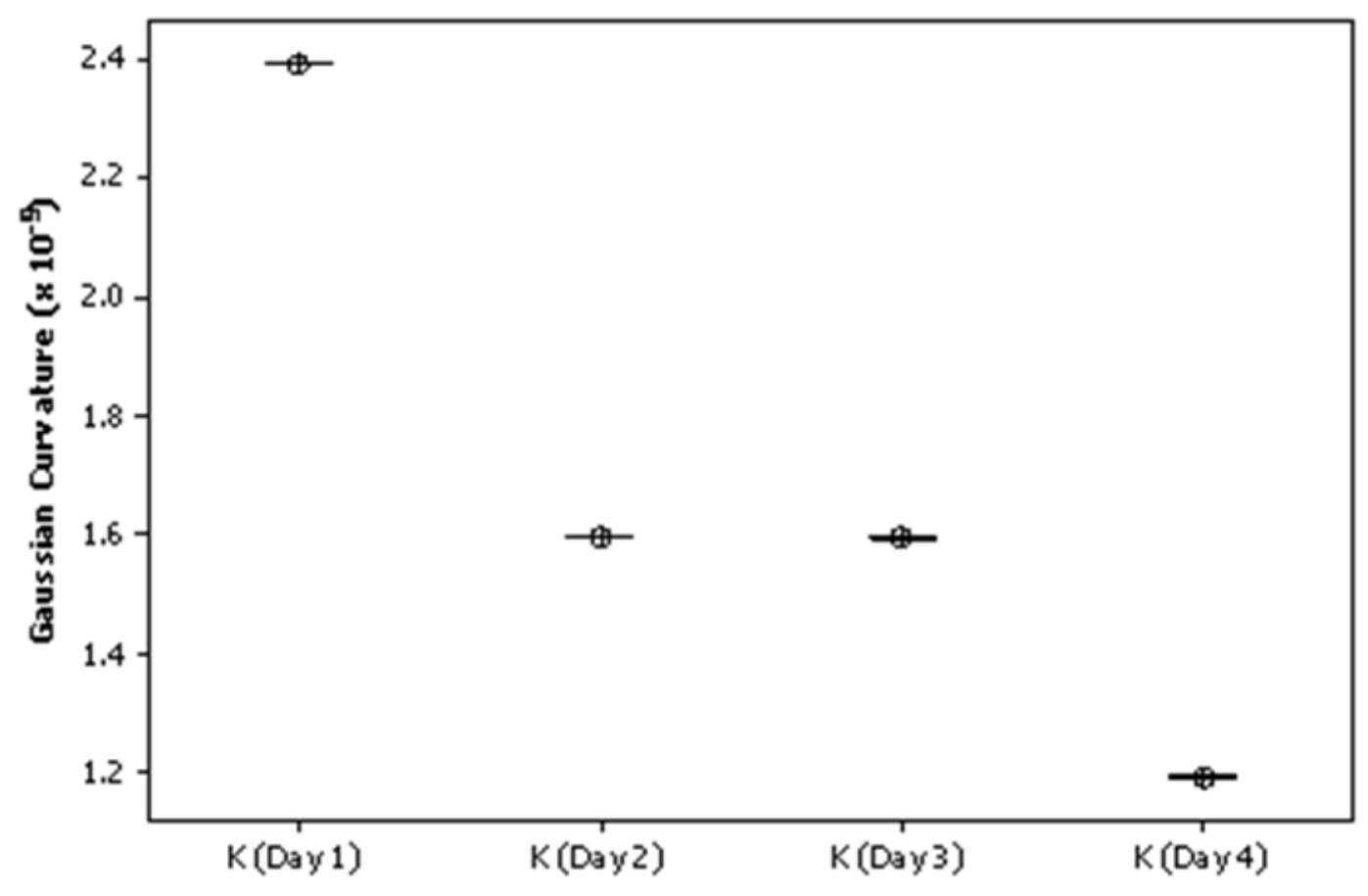

Fig. 8. Calculated Gaussian curvature values of PIR foam panel shrinkage model

Table 4. Descriptive statistics of Gaussian curvatures

\begin{tabular}{lllll}
\hline Variable & Mean & StDev & Min. & Max. \\
\hline Day 1 & $2.3920 \times 10^{-9}$ & 0.00743 & 2.3801 & 2.4006 \\
Day 2 & $1.5962 \times 10^{-9}$ & 0.00496 & 1.5883 & 1.6019 \\
Day 3 & $1.5950 \times 10^{-9}$ & 0.00496 & 1.5870 & 1.6006 \\
Day 4 & $1.1923 \times 10^{-9}$ & 0.00832 & 1.1791 & 1.2018 \\
\hline
\end{tabular}

The worst shrinkage position is defined as $V\left(\frac{b}{2 a}, \frac{b^{2}-4 a c}{4 a}, c\right)$ by correlation and $V\left(\frac{L_{z}}{2}, \frac{L_{y}}{2}, S\right)$ by modeling. Two 2D parabolic functions of both major and minor axes are presented against experimental measurements (Fig 9 and Table 5). The gap between these two indicates more processing non-equilibrium induced density distribution variability under effects of cell irregularity and disorderedness can cause foam structure imbalance and result in possible stress defects. 

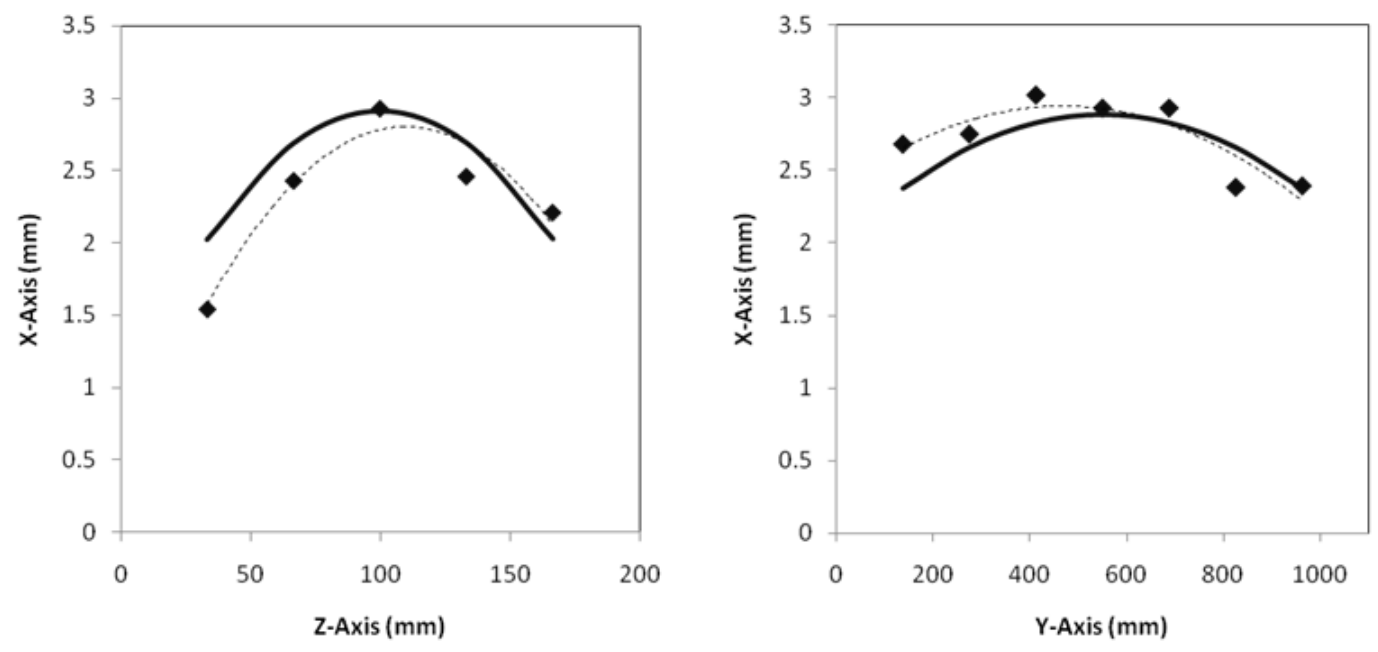

a)
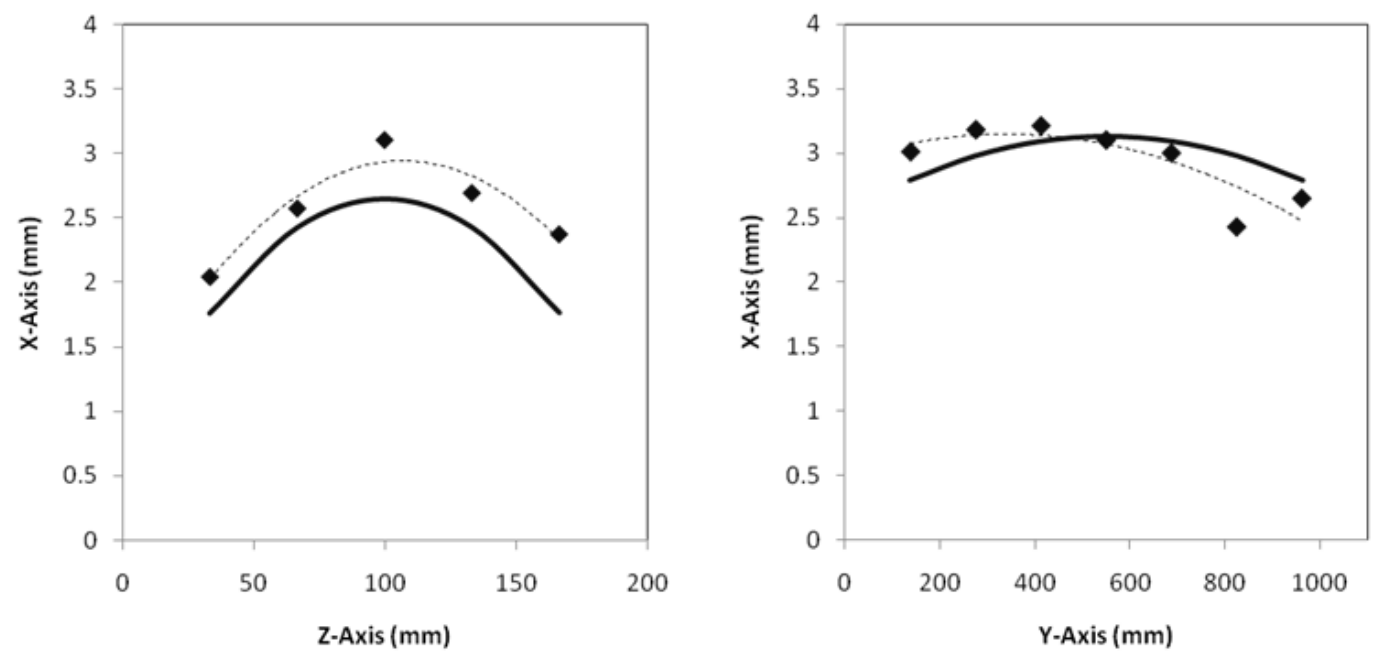

b) 

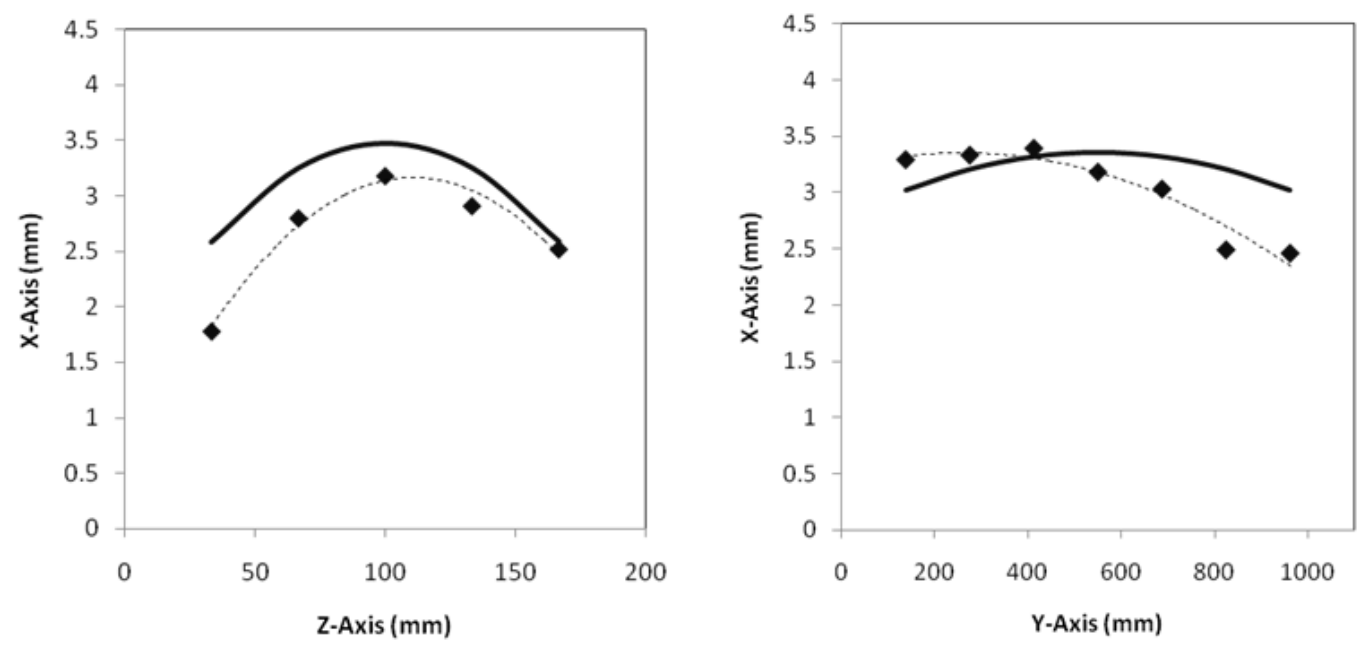

c)
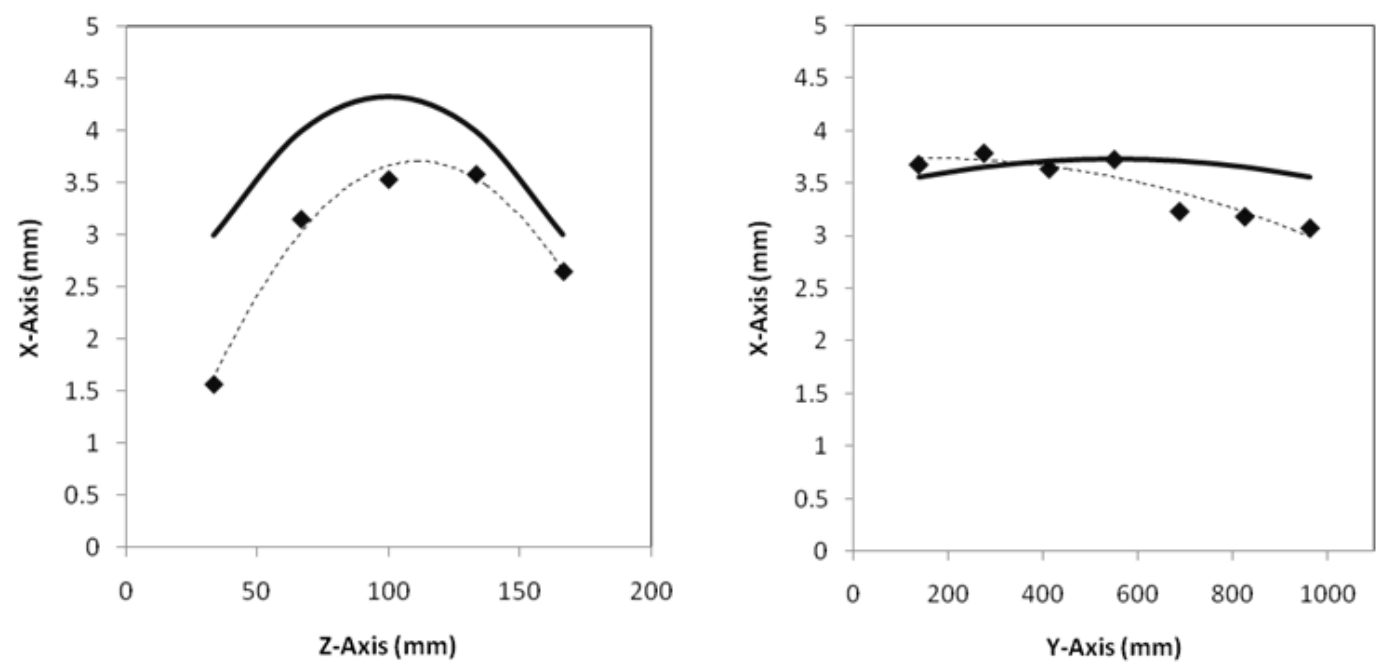

d)

Fig. 9. Shrinkage comparison of actual measurements (dash line) and modelling calculations (solid line) (a) Day 1 (b) Day 2 (c) Day 3 (d) Day 4

Table 5. Deviation tolerance of parabolic vertex

\begin{tabular}{lll}
\hline Tests & Minor $(\mathrm{X}-\mathrm{Z})$ & Major $(\mathrm{X}-\mathrm{Y})$ \\
\hline Day 1 & $-0.63 \%$ & $-1.48 \%$
\end{tabular}



Day 2
$-14.61 \%$
$0.92 \%$
Day 3
$9.32 \%$
$5.70 \%$
Day 4
$22.84 \%$
$0.18 \%$

\section{Microstructure characterization}

After continuous cooling treatment at $-30^{\circ} \mathrm{C}$ for $24 \mathrm{hrs}$, the cell sizes of foam (in-place density $40.5 \mathrm{~kg} / \mathrm{m}^{3}$ ) were measured under SEM and presented over Y-axis (Fig 10). The cell size distribution shows pronounced butterfly shape with more large cells at mid-sec (C) attributed to less constraints of free flow, more small cells at sub-edge due to rheological retardance (L2/R2) under shear and friction effects, and more median cells at edge (L1/R1) with better substrate preservation for cell growth. This distribution doesn't alter significantly after cooling treatment. The protruded downside at L2/R2 indicates possible cell dwindling in cooling at the points of weaker density distribution that was proved by measured core density distribution (Fig 11). The corresponding inverse butterfly suggests the shrinkage distribution is in good proportion to density weakness. This relationship presents more connected at points L2 and R2 where anomalous density weakness corresponds to the worst shrinkage. Furthermore, the observed overall densities increase from cooling treatment can tell the risk of associated collateral damage to cell microstructure when the cell size decreasing extensively under environmental aggressiveness. 


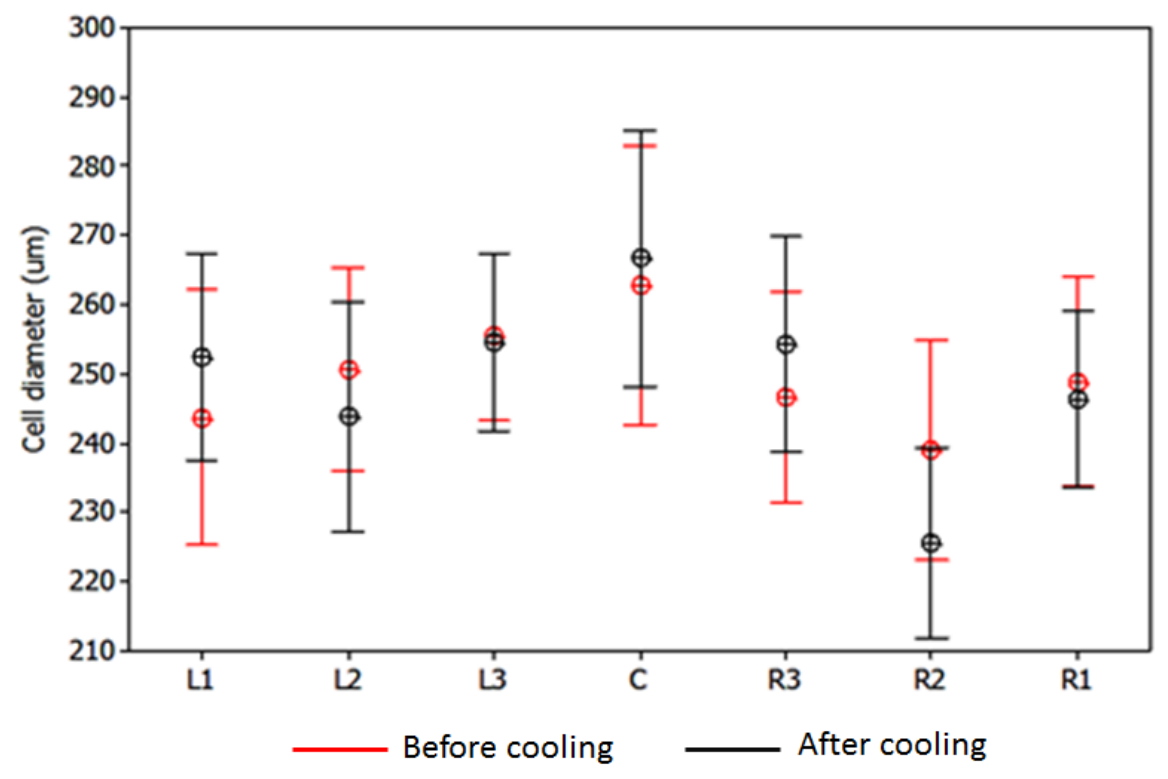

Fig. 10. Cell size distributions before and after cooling treatment (in-place density 40.5 $\mathrm{kg} / \mathrm{m3})$

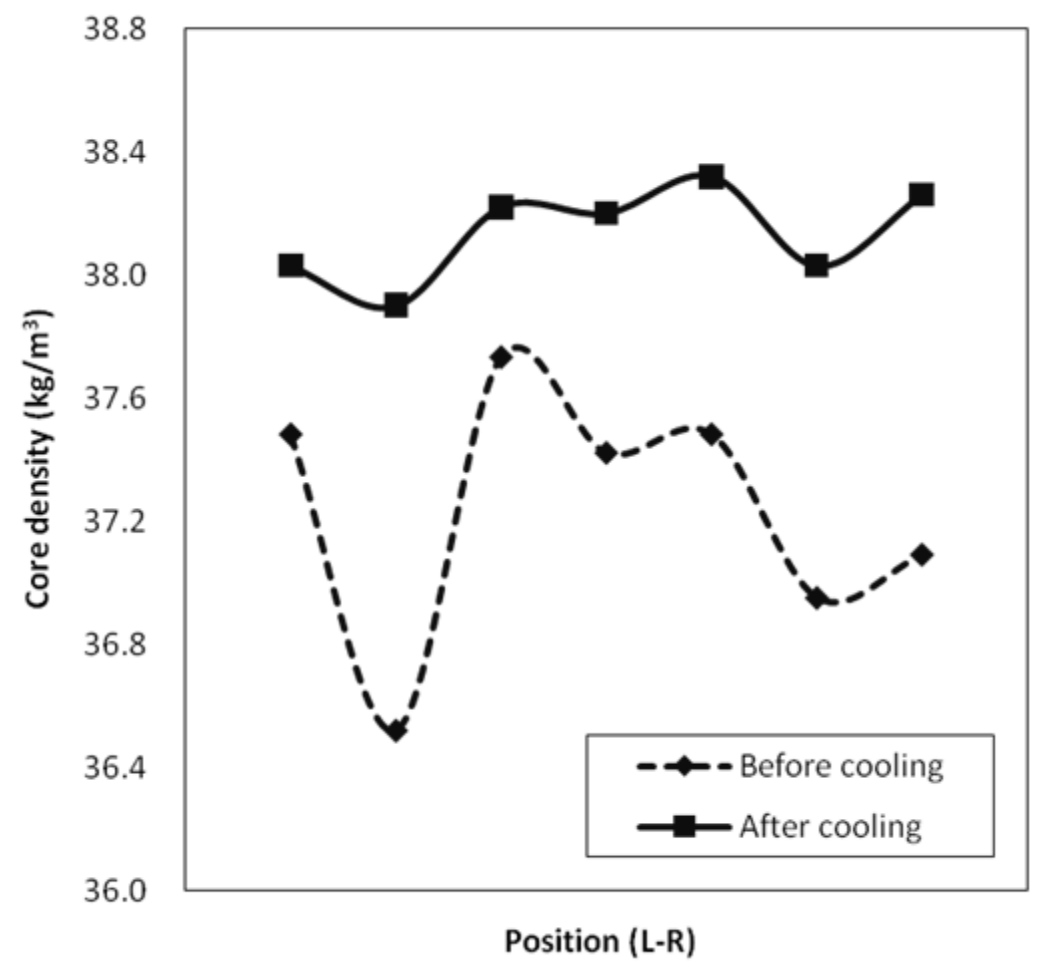

Fig. 11. Core density distributions before and after cooling treatment (in-place density $\mathbf{4 0 . 5}$ $\mathrm{kg} / \mathrm{m3})$ 
The degree of cell anisotropy, defined by aspect ratio of cell horizontal and vertical dimension, is an important measurement to characterize cell growth and foam mico-macro properties. The anisotropic ratios calculations (Fig 12) before and after cooling show a few changes at different points except quite similar average value at mid-sec C (1.445 before cooling and 1.448 after cooling). More changes quite happen at edge sides. Furthermore, the average values on left side L1/L2/L3 are larger than those on right side R1/R2/R3 which suggests the possibility of material flow rate difference. Additionally, the density normality bump at mid-sec $\mathrm{C}$ exhibits much sharper for samples after treatment, which indicates the irregularity and disorderedness are diminishing in cooling.
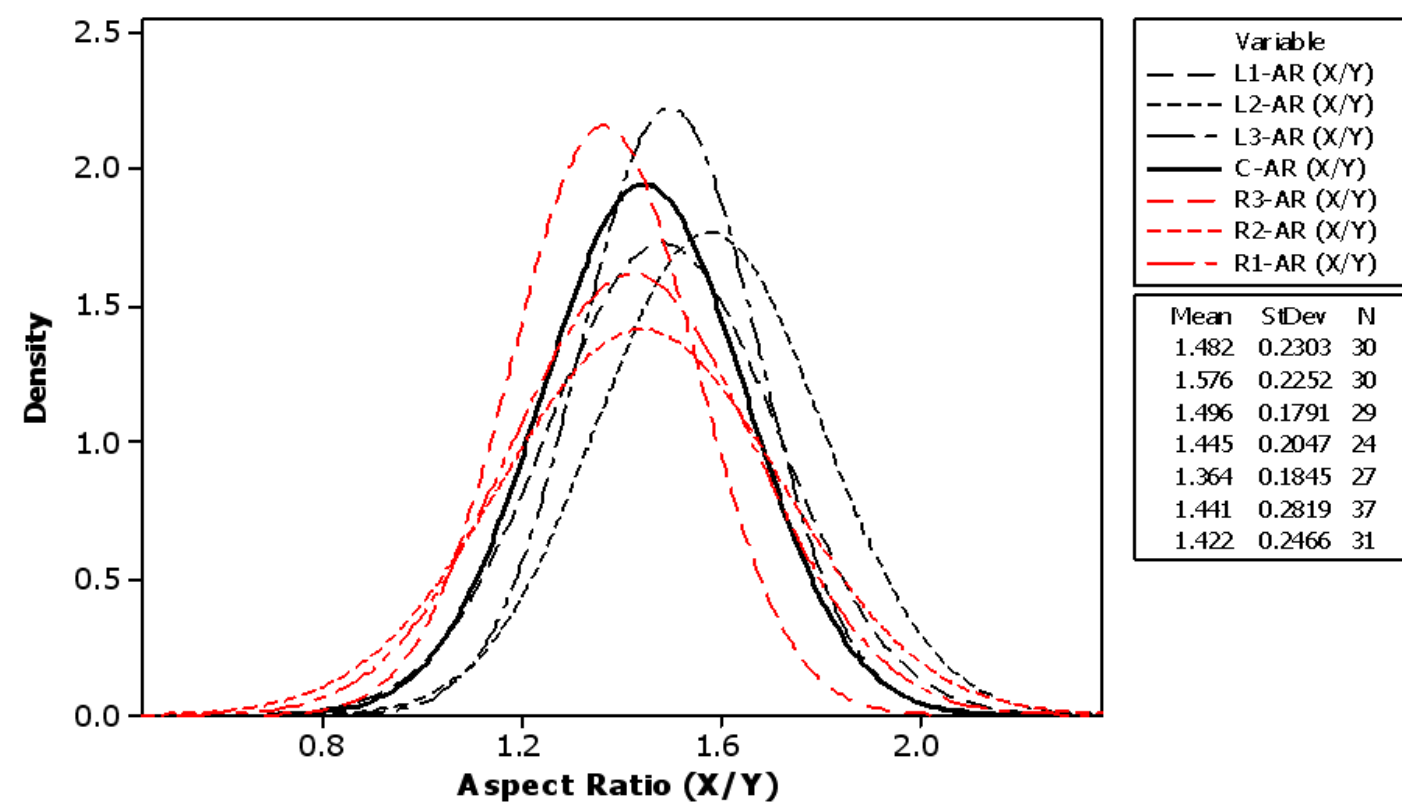

(a) 


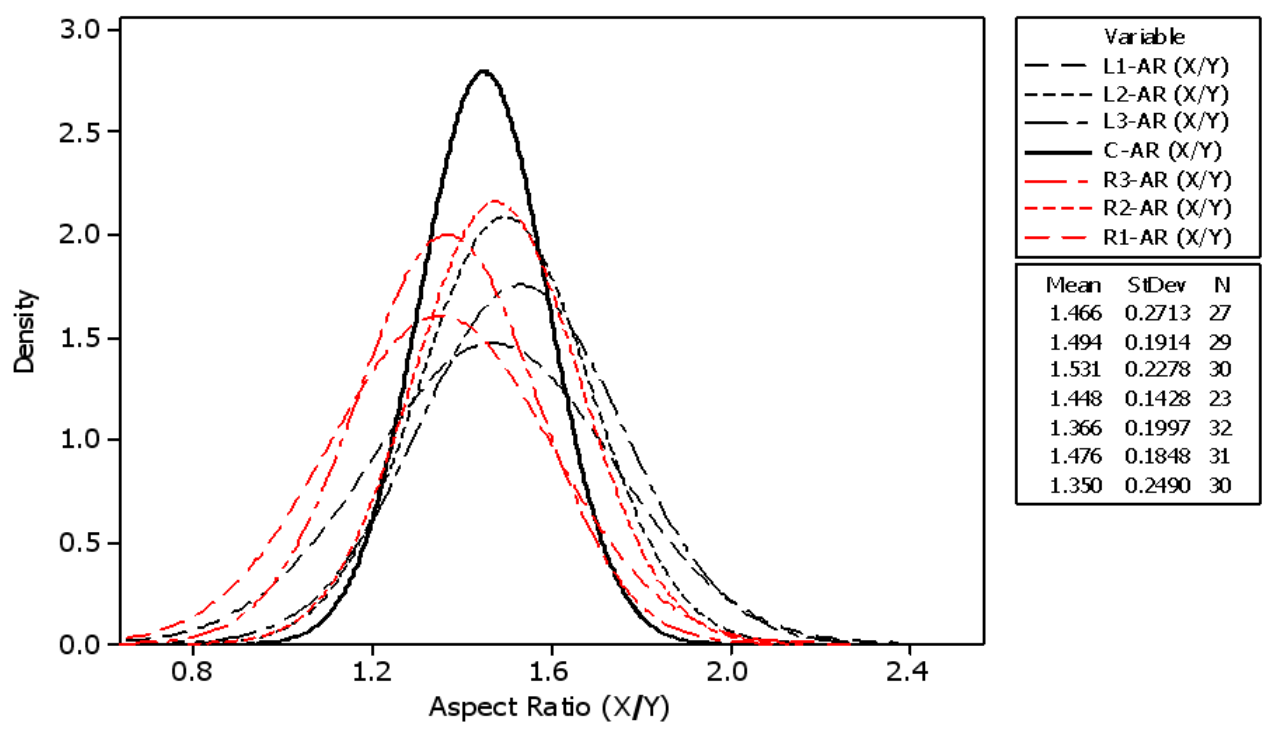

(b)

Fig. 12. Normality distribution of cell isotropic ratios (in-place density $40.5 \mathrm{~kg} / \mathrm{m3}$ ) (a) before cooling (b) after cooling

In relative density equation, the aspect ratio of face thickness to edge length $\left({ }^{t_{f}} / l\right)$ and that of edge thickness to edge length $\left(\mathrm{t}_{\mathrm{e}} / \mathrm{l}\right)$ are two important calculable characterization coefficients. Here in this study, to better understand the possible cellular microgeometric deformations in cooling, these two coefficients were calculated from SEM measured cell voxels (Fig 13). From comparison, all measured cells evidently exhibit smaller $\left(t_{f} / l\right)$ ratio after cooling, which suggests that microscopic deformation occurs on either or both of cell struts and walls. The struts are contracting and/or wall membranes are crumpling during cooling which leads to pressurized deformation. Some stress defects induced strut cracks were observed under SEM which indicates the cells crush may have occurred in cooling treatment (Fig 14). 


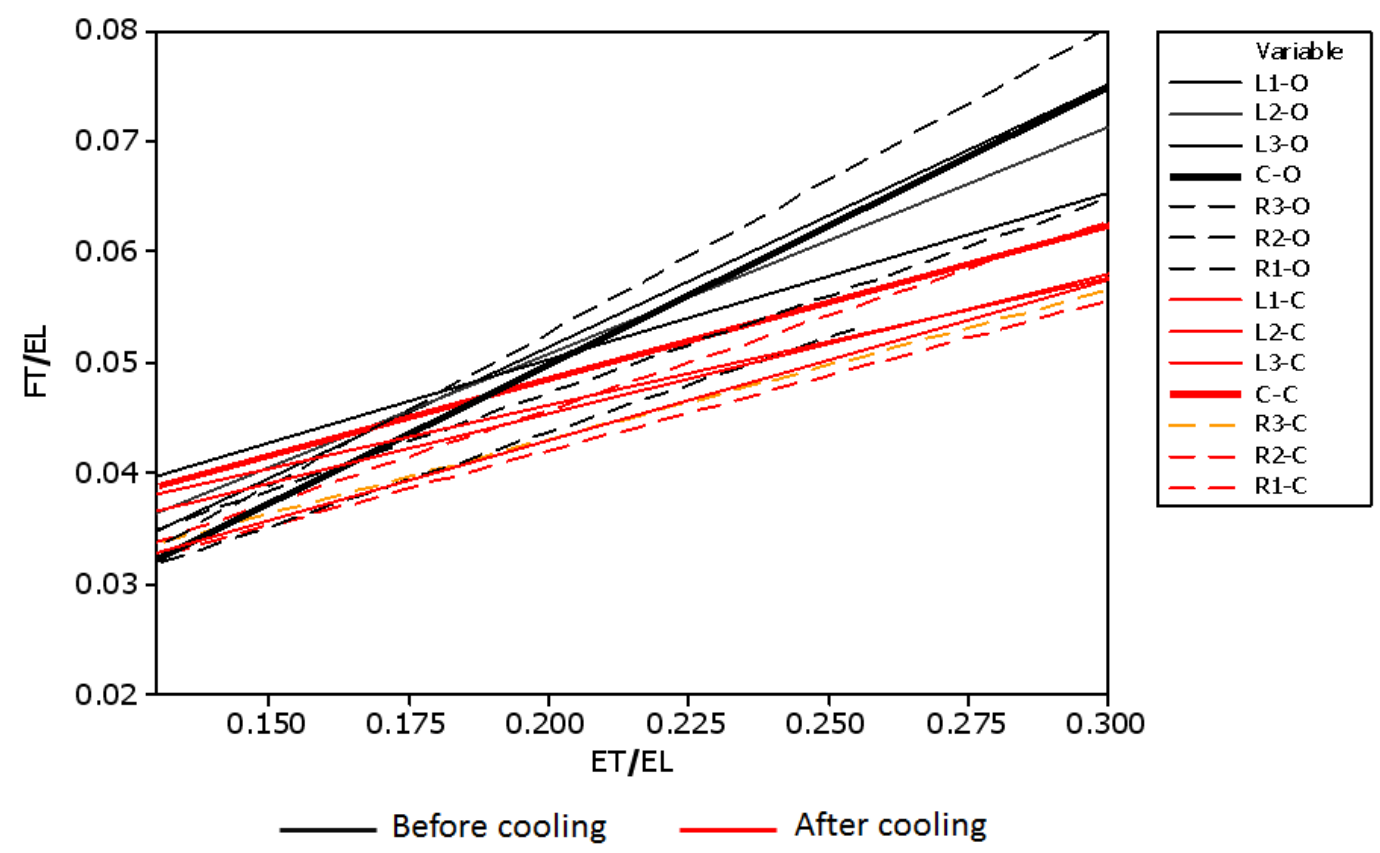

Fig. 13. Foam post-growth deformation after cooling (in-place density $40.5 \mathrm{~kg} / \mathrm{m3}$ )

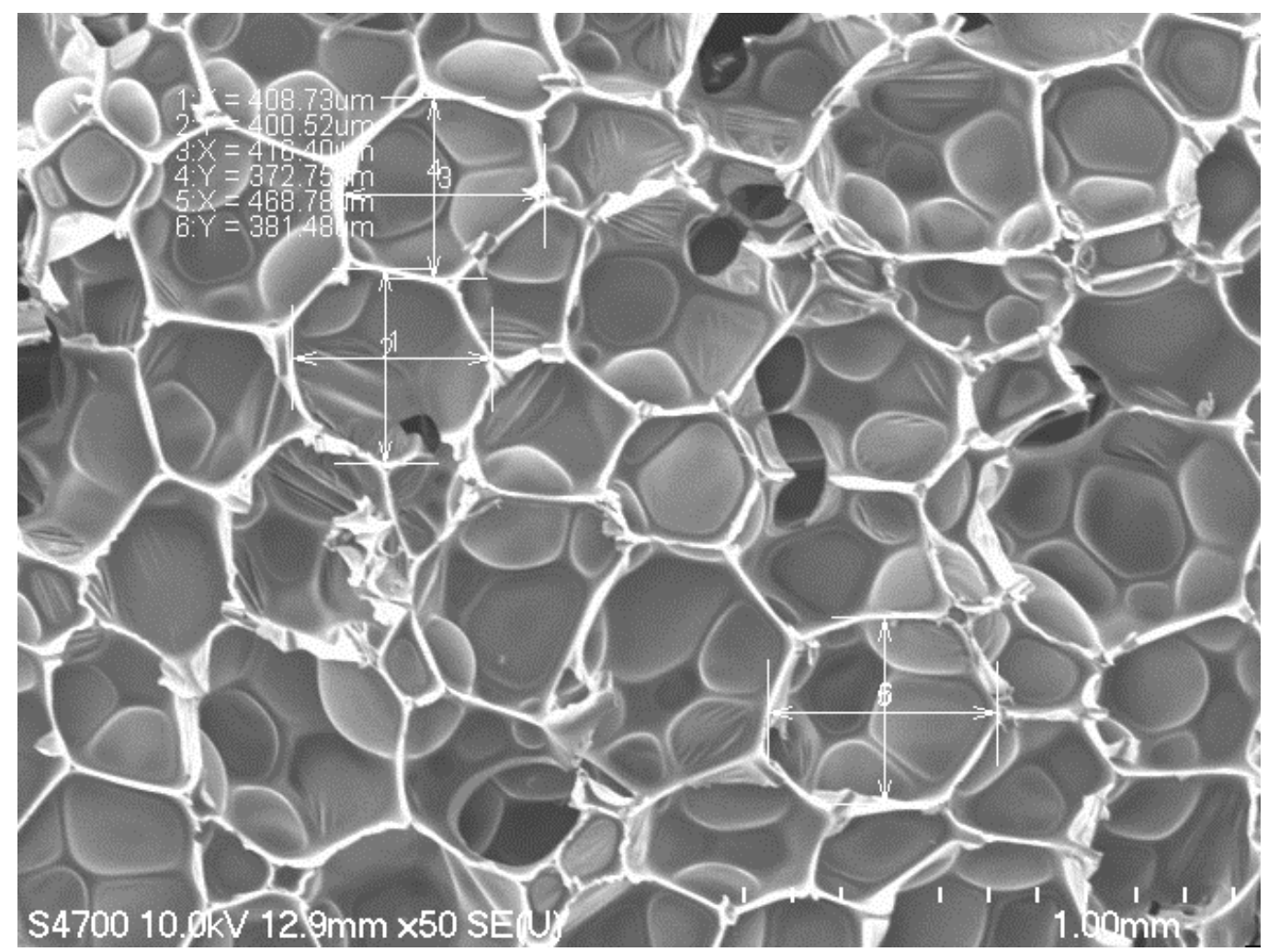

(a) 


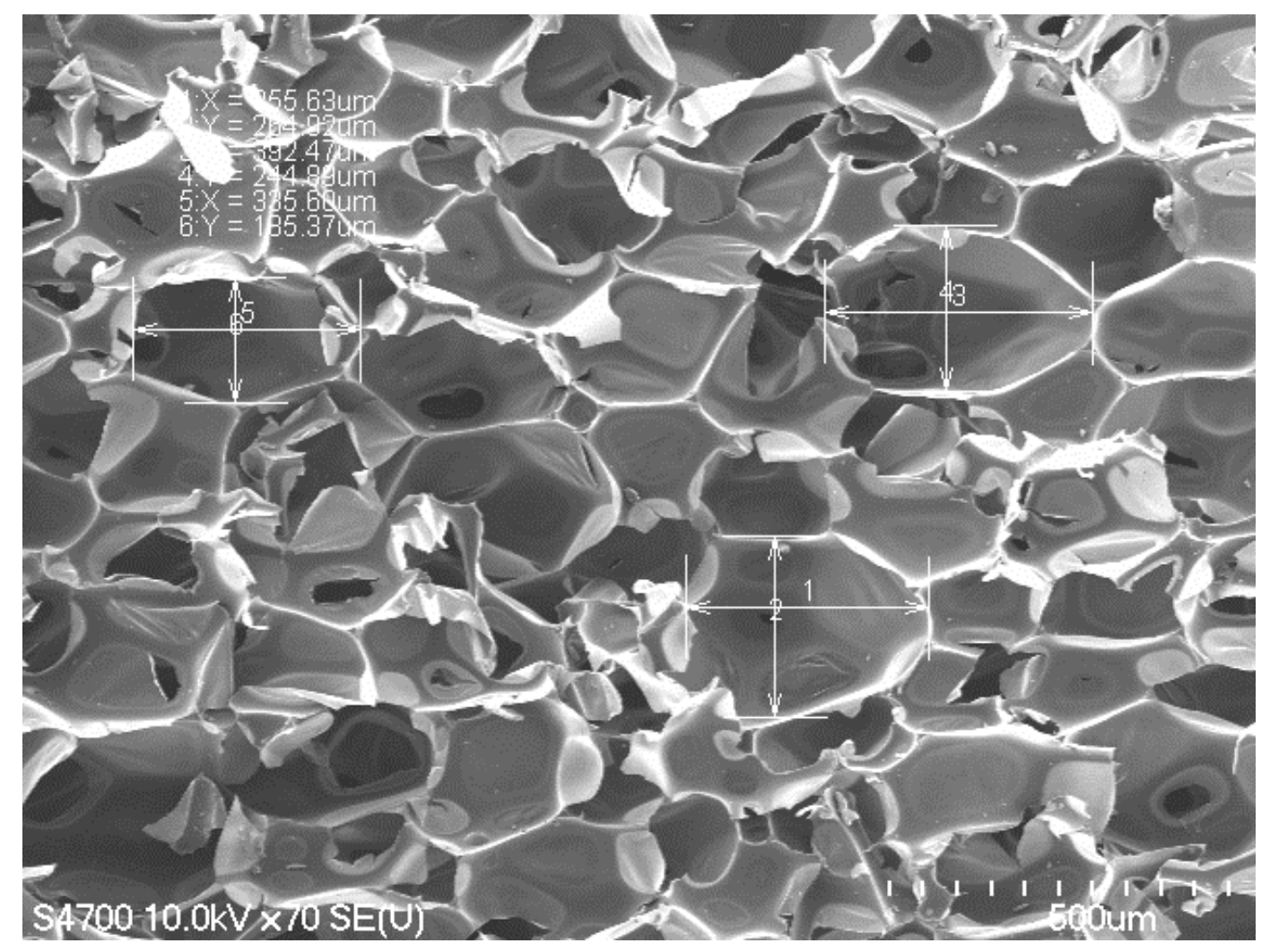

(b)

Fig. 14. Cell microstructure cracks (in-place density $40.5 \mathrm{~kg} / \mathrm{m3}$ ) (a) before cooling (b) after cooling.

The newly defined post-growth angles were proposed to better characterize this microscopic changes. The magnitude of relating deformation becomes evidently identifiable by measuring the angle changes of two calculable aspect ratios $\left(t_{f} / l\right)$ and $\left(t_{e} / l\right)$. The schematic (Fig. 15) illustrates post-growth angles definition at coordinate of $\left(\mathrm{t}_{\mathrm{f}} / \mathrm{l}\right)$ and $\left(\mathrm{t}_{\mathrm{e}} / \mathrm{l}\right) . \quad \theta, \theta_{\mathrm{i}}^{\prime}, \theta_{\mathrm{d}}^{\prime}$ denote original angle, inflation angle, and deflation angle respectively. 


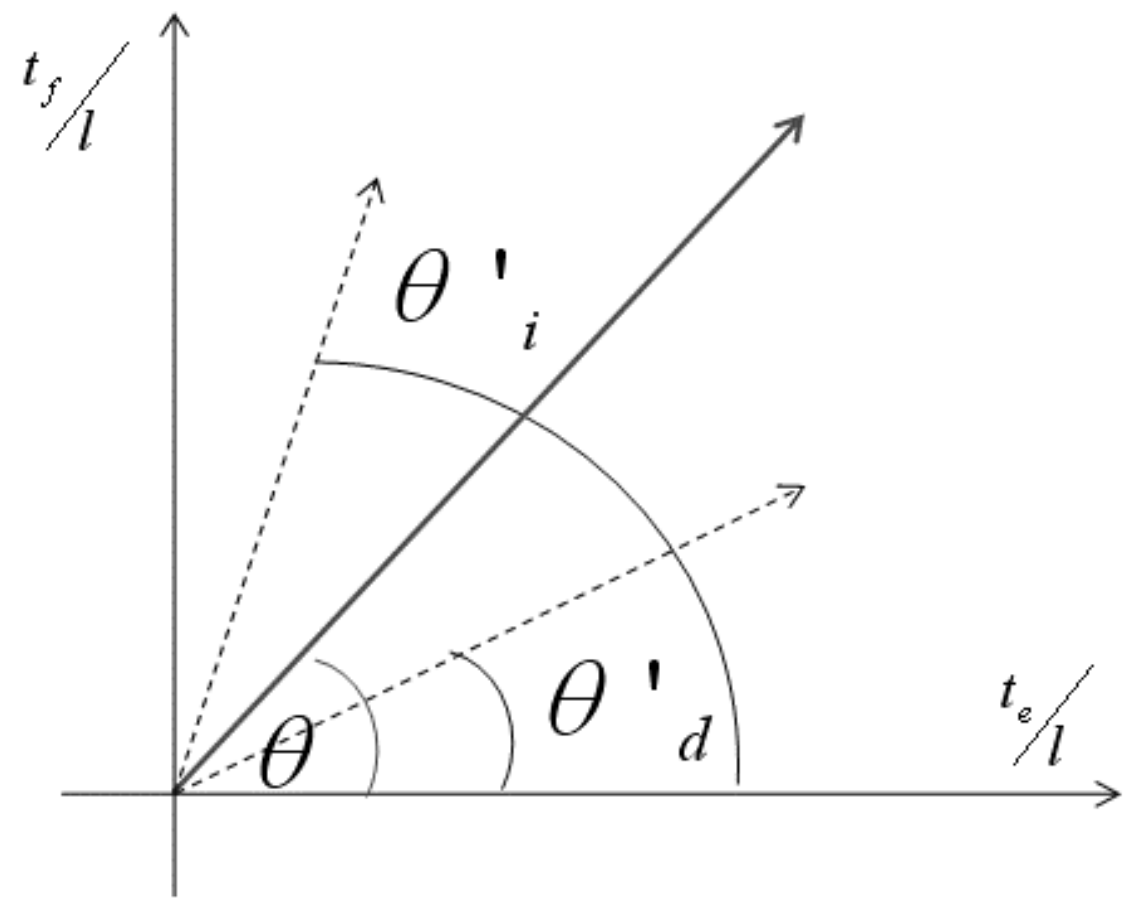

Fig. 15. Schematic diagram of post-growth angle definition

Further evaluations on these post-growth angles through trigonometric functions give three postgrowth coefficients $\varepsilon, \varepsilon_{\mathrm{i}}, \varepsilon_{\mathrm{d}}$ which denotes overall post-growth coefficient, inflation coefficient and deflation coefficient respectively. Usually as calculated, $\varepsilon_{\mathrm{i}}>1$ and $\varepsilon_{\mathrm{d}}<1$.

$$
\begin{gathered}
\varepsilon_{\mathrm{i}}=\frac{\tan {\theta^{\prime}}_{\mathrm{i}}}{\tan \theta} \\
\varepsilon_{\mathrm{d}}=\frac{\tan {\theta^{\prime}}_{\mathrm{d}}}{\tan \theta}
\end{gathered}
$$

Then

$$
\varepsilon=\frac{\varepsilon_{\mathrm{i}}}{\varepsilon_{\mathrm{d}}}=\frac{\tan \theta^{\prime}}{\tan \theta_{\mathrm{d}}^{\prime}}
$$

\section{Blowing and foaming process}

\section{Blowing agent effects}


The foam rise records in FOAMAT reactivity profile provide effective evaluation tool to blowing agent competence and appropriateness. Blowing agent with higher boiling point has relatively slower rise at around cream time (CT) and faster growth at around gel time (GT) (Fig.16). This higher boiling point attributes to high molecular polarity and strong intermolecular interactions induced by chloride atom which leads to slower kinetic energy increase by heating. In other words, internal energy increase rate over temperature is lower for blowing agents with higher boiling point. This is termed as heat capacity which can be understood as entropy of vaporization defined as isochoric enthalpy change rate at temperature of boiling point. Higher enthalpy of blowing agents with lower boiling point leads to higher work by faster volumetric expansion at corresponding pressure constant and results in faster foam rise at phase transition around cream time (CT). Foam rise continues with increasing freedom of disorderness in both volume expansion and pressure increase till thermodynamic equilibrium. The simultaneous diffusion rate is also governed by molecular structure and attached functional groups. Lower boiling point is in correspondence with higher diffusion rate which indicates more gaseous mass flow of molecules transmission with more heat transfer through cell interface that hinders further polymerization and crosslink. This reaction extension slowdown occurring around gel time (GT) results in slower foam rise. The difference of foaming effectiveness $F$ can be measured by the maximum distance between tangent lines of two rise curves when two lines are parallel at the curvature vertex which is usually the point at boiling point temperature and the turning point of foam rise acceleration rates (Fig 16). The acceleration rate is second derivative of measured rise $H(T)$ which is maximized at vertrex with corresponding temperature $T$ at boiling point. 


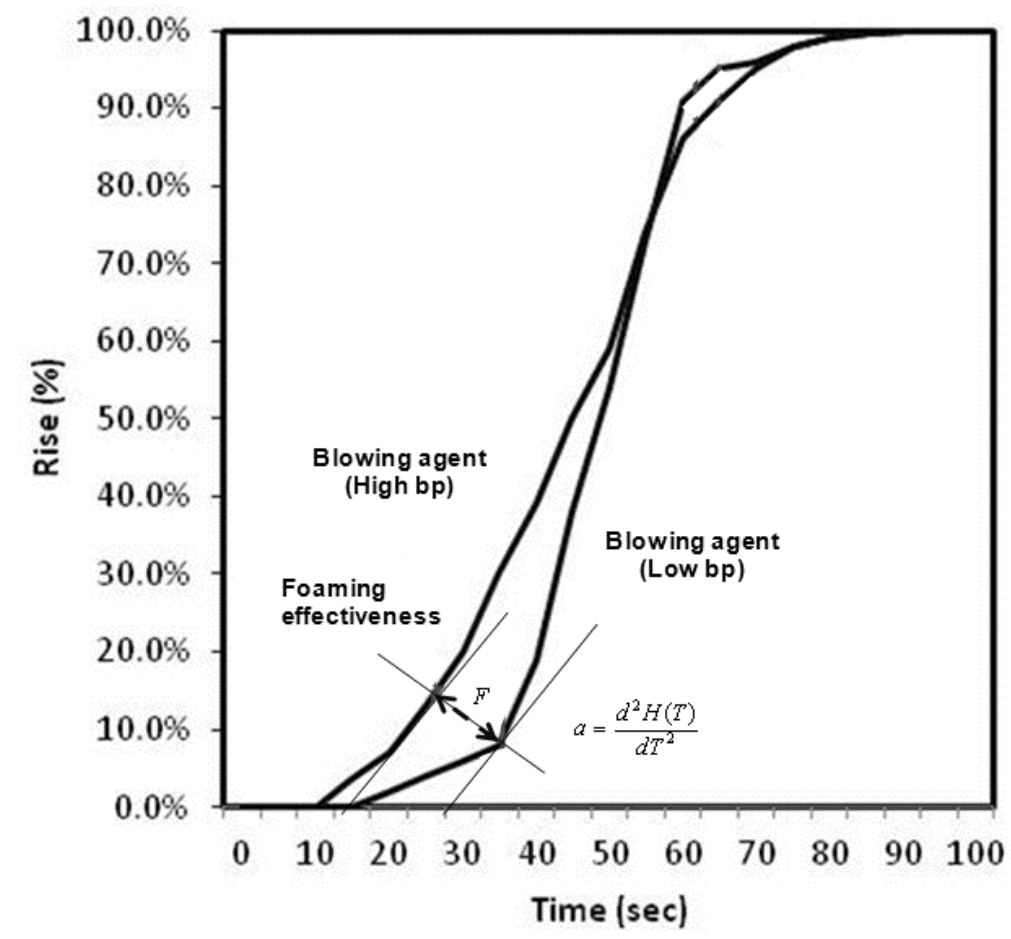

Fig. 16. Schematic diagram of foam rise with blowing agents

\section{Foaming process}

The well recorded time features (CT/GT/TFT) of reactivity profiling in FOAMAT can provide informative diagnosis of great scientific significance on processing optimization. In case of continuous PIR panel production, the productivity optimization can be achieved by acceleration efforts at both line running (X-axis) and foam rise (Y-axis) directions:

- Higher foam rise (Fig 17a)

The foam rise height is related to amount of blowing agents in formulation. The driving force at $\mathrm{Y}$-axis is dependant variable of blowing agent fractions which is measurable from free rise foam growth. More blowing agents can narrow the materials touch face time and increase flowability at domain close to top face.

- $\quad$ Faster face touch (Fig 17b)

The material touch face time can also be narrowed by accelerating foam rise speed. The foam increasing rate can be improved by more catalyzation. More catalysts can make 
foam grow along the curve with larger lean angle towards right angle within shorter time. More catalysts cannot change the rise height but can improve the rise rate.

- Faster line speed (Fig 17c)

Fast line speed may escalate management difficulties and needs better materials feedstock management. Increasing line speed leads to longer distance running within unit time which can be characterized by unit displacement from $V_{l}$ to $V_{l}{ }^{\prime}$. It leads to feedstock volume increase which is characterized as area expansion of geometric triangle with displacement. That means more materials are needed but foam in-place density still remains constant due to the proportionally increased empty volume.

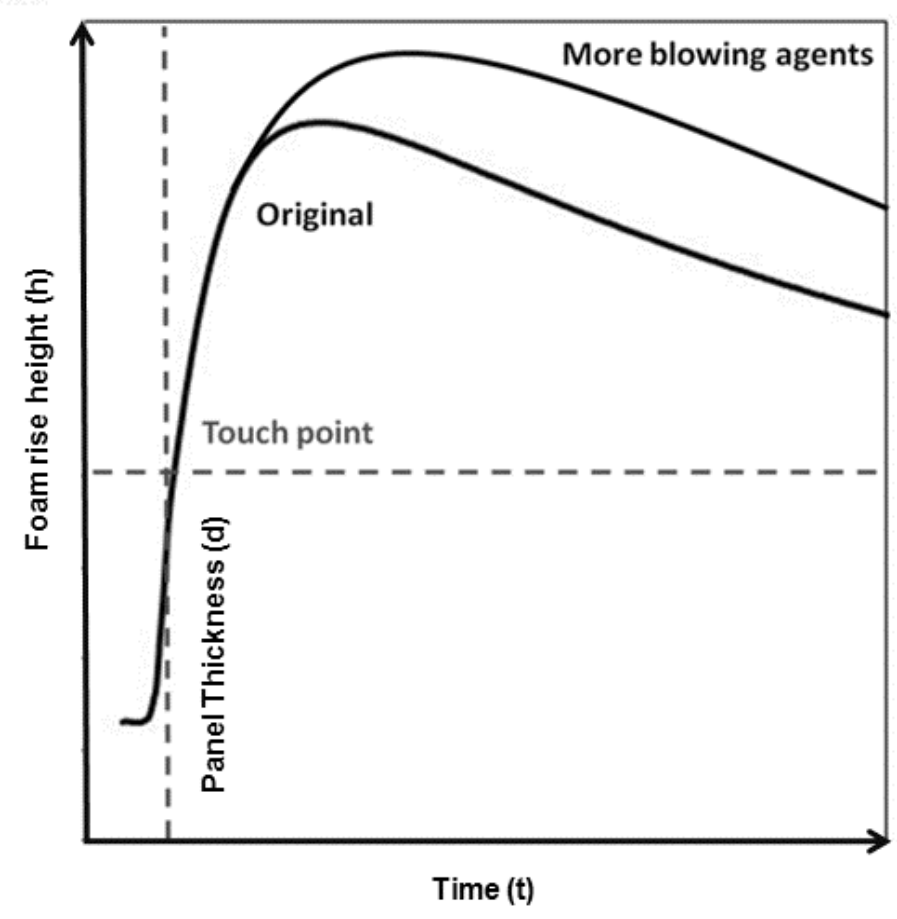

(a) 


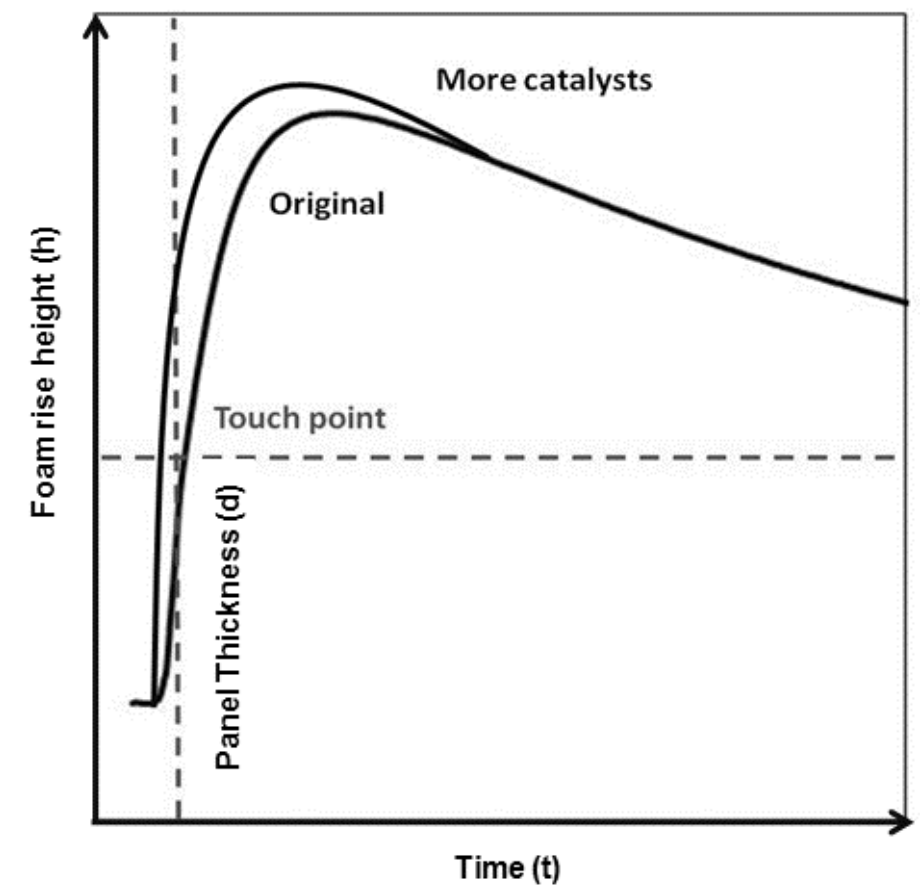

(b)

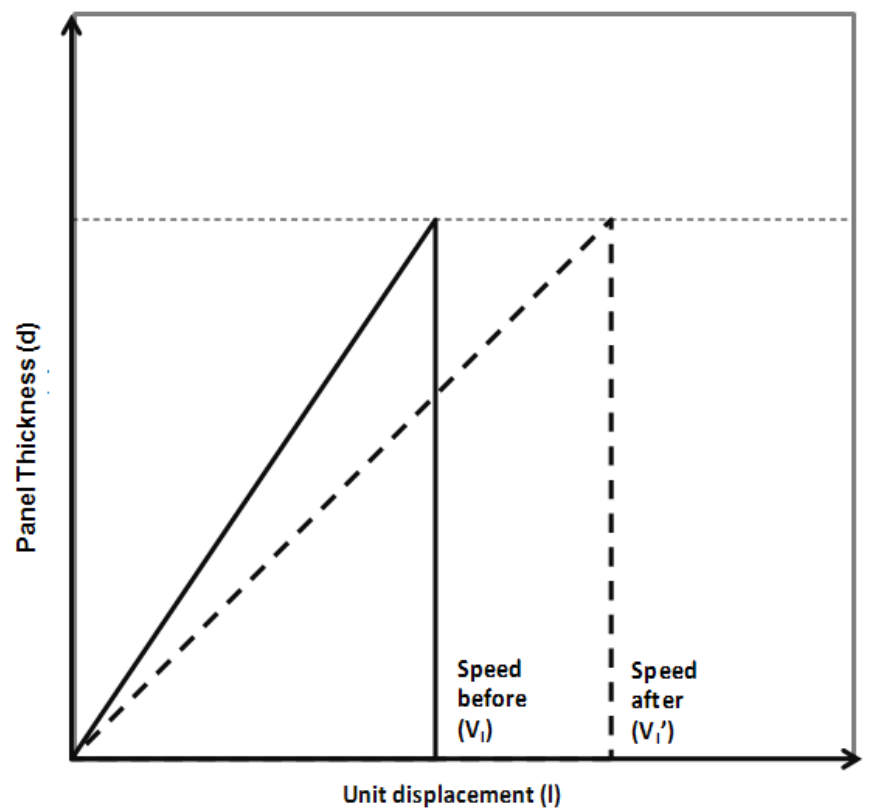

(c)

Fig. 17. Schematic diagrams of continuous PIR foam panel production optimization methods (a) by blowing agents (b) by catalysts (c) by line speed 
Foam rise starts at lay-down point when $t=0$ and then continues growing and deforming under line motion generated acceleration. Assuming constant mass of materials laying down on start point, foam rise is driven by vector sum force of vapor pressure from blowing agents vaporization at $\mathrm{Y}$-axis and inertia force from line motion at $\mathrm{X}$-axis with vector angle $\theta$ (Fig 18).

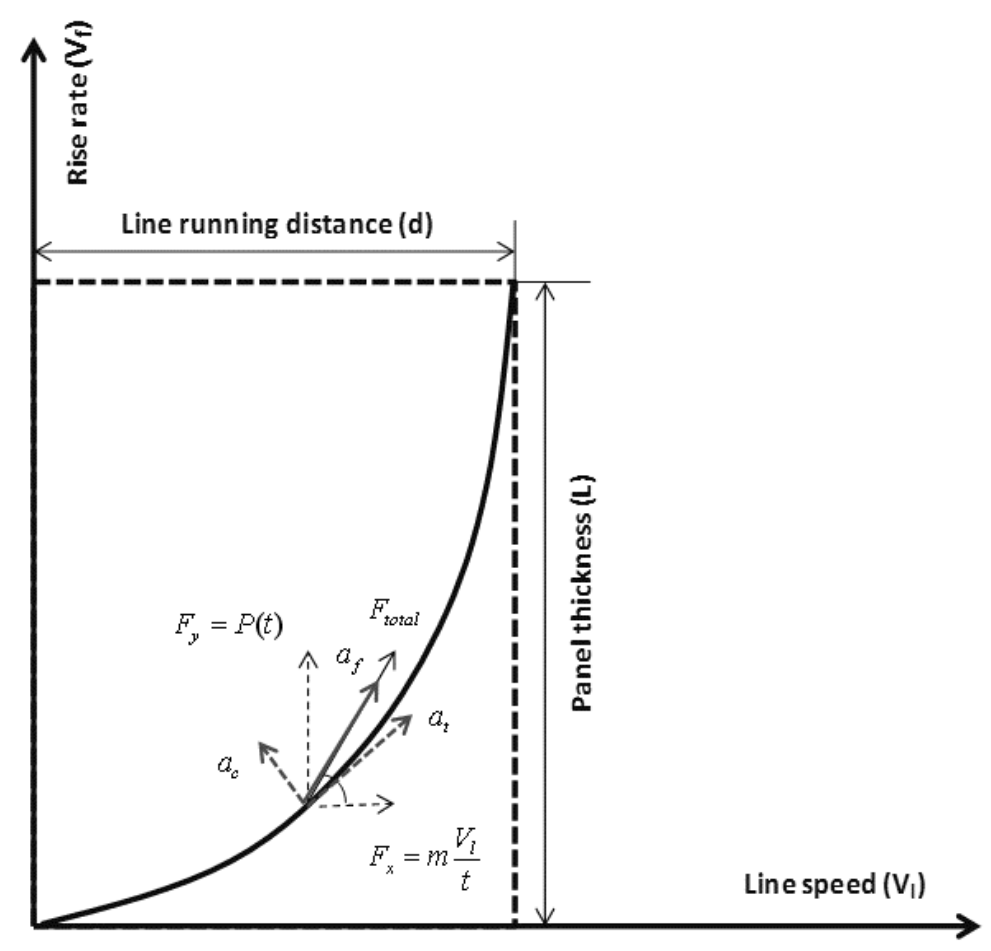

Fig. 18. Schematic diagram of foam rise in PIR foam panel continuous line production

Then the foam growth can be characterized by magnitude and vector evaluation. The forces in biaxis were presented:

$$
\begin{gathered}
F_{x}=m a_{l}=m \frac{V_{l}}{t} \\
F_{y}=P(t)
\end{gathered}
$$

Where $m$ denotes material mass, $V_{l}$ denotes line speed, $P(t)$ denotes recorded partial pressure from FOAMAT normalized by mass $m$. Then total force $F_{\text {total }}$ can be vector sum of two components in bi-axis: 


$$
F_{\text {total }}=F_{x} \cos \theta+F_{y} \sin \theta=\frac{m V_{l}}{t} \cos \theta+P(t) \sin \theta
$$

The vector angle can be obtained from trigonometic inverse calculation on aspect ratio of foam rise and line displacement in unit time:

$$
\theta=\arctan \frac{H(t)}{V_{l} t}
$$

Where $H(t)$ is recorded FOAMAT foam rise with respect to time $t$ normalized by mass $m$.

The total force generated acceleration is also vector sum of components tangential $a_{t}$ and centripetal $a_{c}$ which is derivable from net force $F_{\text {total }}$ action on body with mass quantities $m$ in terms of Newton's second law.

$$
a=\frac{m V_{l} \cos \theta+P(t) t \sin \theta}{t m}
$$

Thus the foam rise in continuous production $H$ can be solved by second order integrals:

$$
H=\iint \frac{m V_{l} \cos \theta+P(t) t \sin \theta}{t m} d t^{2}
$$

\section{Conclusion}

The polyurethane insulation performance, post-stability and foaming process were re-assessed by theoretical standard calculation, 3D paraboloid modelling, microstructural characterization, and processing modelling.

As calculated by cold warehouse design standard, the insulation thickness values of polyurethane foam made from HCFC-141b/HFC-245fa blends are much lower than those calculated from recommended data $(0.024 \mathrm{~W} / \mathrm{m} \cdot \mathrm{K})$ which strongly suggests the energy saving can be achieved by using HCFC-141b/HFC-245fa blends polyurethane sandwich panels, and the thickness reduction can be made or cost efficiency on power saving can be attained without compromising insulation performance. 
3D paraboloid shrinkage model under panel size boundary was developed based on idealized elliptic paraboloid functions evaluation through 2D parabolic correlation. The comparison between modeling results and experimental measurements tells the panel post-cure instability under impacts by processing non-equilibrium and incurred heterogeneousness. Newly defined inflation-deflation angle coefficients were proposed which makes cell microstructural deformation characterization even more practically measurable.

Physical blowing agent is capable of leveraging the polyurethane foaming process by fast vaporization with low kinetic energy requirement over thermodynamic equilibrium. The foaming effectiveness of two different blowing agents with low and high boiling points can be characterized by distance gap between two foam rise curves at curvature vertex. Productivity improvement is attemptable by higher foam rise using more blowing agents, faster face touch using more catalysts, and faster line speed by more feedstock. The foam growth in continuous production can be characterized by magnitude and vector evaluation of acceleration functions.

\section{Acknowledges}

This work was supported by the NSFC (Grant No. 21403119). The authors would like to thank the kind assistance offered by the Honeywell Shanghai Lab for analytical works, Jiangsu Jingxue for providing trial opportunities and panel specimens, and Bayer China, BASF China, and Wanhua China for supplying the pre-blended polyols and isocyanates for this study.

\section{References}

Asdrubali, F., and Baldinelli, G. (2011). "Thermal transmittance measurements with the hot box method: calibration, experimental procedures, and uncertainty analyses of three different approaches.” Energy Build., 43, 1618-1626

Asdrubali, F., D'Alessandro, F., Baldinelli, G., and Bianchi, F. (2014). "Evaluating In Situ Thermal Transmittance of Green Buildings Masonries - A Case Study.” Case Stud. Constr. Mater., 1, 53

ASTM C518-10. (2010). Standard Test Method for Steady-State Thermal Transmission Properties by Means of the Heat Flow Meter Apparatus. 
Baldinelli, G., and Bianchi, F. (2014). "Windows thermal resistance: infrared thermography aided comparative analysis among finite volumes simulations and experimental methods." Appl. Energy, 136, 250-258

Baser, S. A., and Khakhar, D. V. (1994). "Modeling of the dynamics of R-11 blown polyurethane foam formation." Polym. Eng. Sci., 34(8), 632-641.

Baser, S. A., and Khakhar, D. V. (1994). "Modeling of the Dynamics of Water and R-11 blown polyurethane foam formation.” Polym. Eng. Sci., 34(8), 642-649.

Bikard, J., Bruchon, J., Coupez, T., and Vergnes, B. (2005). "Numerical prediction of the foam structure of polymeric materials by direct 3D simulation of their expansion by chemical reaction based on a multidomain method." J. Mat. Sci., 40(22), 5875-5881.

Bikard, J., Bruchon, J., Coupez, T., and Silva, L. (2007). "Numerical simulation of 3D polyurethane expansion during manufacturing process." Coll. \& Surf. A: Physicochemical and Eng. Aspects 309(1), 49-63.

BRE Client Report No. 78132. (2000). Building Research Establishment, Field investigations of the thermal performance of construction elements as built.

Chattopadhyay, D. K., and Webster, D. C. (2009). "Thermal stability and flame retardancy of polyurethanes." Prog. Polym. Sci., 34(10), 1068-133.

EN 12664. (2001). Thermal Performance of Building Materials and Products - Determination of Thermal Resistance by Means of Guarded Hot Plate and Heat Flow Meter Methods - Dry and Moist Products of Medium and Low Thermal Resistance.

EN 12667. (2001). Thermal Performance of Building Materials and Products — Determination of Thermal Resistance by Means of Guarded Hot Plate and Heat Flow Meter Methods Products of High and Medium Thermal Resistance.

EN 12939. (2000). Thermal Performance of Building Materials and Products - Determination of Thermal Resistance by Means of Guarded Hot Plate and Heat Flow Meter Methods - Thick Products of High and Medium Thermal Resistance.

EN ISO 8990. (1996). Thermal Insulation — Determination of Steady-state Thermal Transmission Properties - Calibrated and Guarded Hot Box (ISO 8990:1994). 
EN 12567-1. (2010). Thermal Performance of Windows and Doors - Determination of Thermal Transmittance by the Hot-box Method Complete Windows and Doors.

GB 50072 - 2010. (2010). China Code for Design of Cold Store

Geier, S., Winkler, C., and Piesche, M. (2009). "Numerical simulation of mold filling processes with polyurethane foams." Chem. Eng. \& Tech., 32(9), 1438-1447.

Guo, A., Javni, I., and Petrovic Z. (2000). "Rigid polyurethane foams based on soybean oil.” J. Appl. Polym. Sci., 77 (2), 467-473.

Haberstroh, E., and Zabold, J. (2004). "Modelling and simulation of the foam formation process." J. Polym. Eng. 24(1-3), 377-390.

ISO 6946. (2007). Building Components and Building Elements — Thermal Resistance and Thermal Transmittance - Calculation Method.

Jarfelt, U., and Ramnas, O. (2006). "Thermal conductivity of polyurethane foam - best performance, Clamers Univeristy of Technology." 10th International Symposium on District Heating and Cooling, Goteborg, Sweden.

Kuhn, J., Ebert, H. P., Arduini-Schuster, M. C., Büttner, D., and Fricke, J. (1992). “Thermal transport in polystyrene and polyurethane foam insulations." Int. J. Heat Mass Transf., 35(7), 1795-801.

Mao, D., Harvey, A. D. , and Edwards, J.R. (2005). “Development of low-diffusion flux-splitting methods for gas-liquid flows with interface propagation and phase variation." Wittransactions on Eng. Sci., 50, 327.

Monteavaro, L.L., da Silva, E.O., and Costa, A.P.O. (2005). "Polyurethane networks from formiated soy polyols: Synthesis and mechanical characterization.” JAOCS, 82(5), 365-371.

Patent No. 3621819 and 19730891, Foam qualification system FOAMAT, Labomat Instruments and Specialties.

Seo, D., and Youn, J. R. (2005). "Numerical analysis on reaction injection molding of polyurethane foam by using a finite volume method.” Polymer, 46(17), 6482-6493.

Thomas, G.B., Maurice, D., Weir, J. H., and Giordiano, F. R. (2005). Thomas' Calculus 11th ed. Pearson Education, Inc. p. 892. 
Wu, J. W., Sung, W. F., and Chu, H. S. (1999). "Thermal conductivity of polyurethane foams.” Int. J. Heat Mass Transf., 42(12), 2211-7. 